\title{
Oxidation Behavior of Tungsten Carbide-6\% Cobalt Cemented Carbide
}

\author{
C. Bagnall ${ }^{1} \cdot$ J. Capo $^{2} \cdot$ W. J. Moorhead ${ }^{2}$
}

Received: 4 May 2018 / Revised: 28 September 2018 / Accepted: 11 October 2018 / Published online: 15 November 2018

c) Springer Science+Business Media, LLC, part of Springer Nature and ASM International 2018

\begin{abstract}
This paper examines the oxidation behavior of annular tungsten carbide- $6 \%$ cobalt binder samples, after exposure to air furnace temperatures in the range $500-1100{ }^{\circ} \mathrm{C}$. An unreacted shrinking core model is supported by evidence of surface reactions on the OD surface. However, significant changes are noted on the ID surface of the annulus, indicating a change in oxidation mechanism. Oxidation products and oxide structure become more complex with increasing temperature. These phenomena are explored in terms of oxide formation, oxidation rate, and exposure temperature.
\end{abstract}

Keywords Cemented carbides · Oxidation behavior $\cdot$ Cobalt $\cdot$ Elevated temperature $\cdot$ Annular geometry

\section{Introduction}

This study of WC-6\% Co cemented carbide oxidation was instigated by a failure analysis. The system in question had been working well for a number of years, and then improvements were made that resulted in defective operation. In this instance, the malfunction focused on small annular bushings, installed in a nozzle for fluid pressure control, in an oil drilling application. The bushings, which are $\sim 9 \mathrm{~mm}$ in diameter with a small central hole, were installed by shrink-fitting them into a tube assembly.

The failure analysis investigation focused on an unexpected oxide formation on the ID surface of the small bushings, which had an adverse effect on fluid flow through the annulus. Oxide formed on the exposed bushing surfaces during a late-stage heat treatment operation.

This article is an invited paper selected from presentations at "Fifty Years of Metallography and Materials Characterization," a symposium celebrating the 50th Anniversary of the International Metallographic Society, held during MS\&T'17, October 8-12, 2017, in Pittsburgh, Pa., and has been expanded from the original presentation.)

\section{Bagnall}

chris.mcs@pes-testing.com

1 MCS Associates, Inc., 637 Donohoe Road, Latrobe, PA 15650, USA

2 Product Evaluation Systems, Inc., 637 Donohoe Road, Latrobe, PA 15650, USA
These observations, and a laboratory evaluation of bushings removed from service, became the groundwork for this study. Initial oxidation experiments with bushings in the range $500-700{ }^{\circ} \mathrm{C}$ were expanded to encompass behavior up to $1100^{\circ} \mathrm{C}$. In addition, the annular geometry of the bushing provided a unique test-sample platform for observing the nature of volume change that accompanies oxidation reactions on WC-Co cemented carbide materials.

\section{Background}

There is a wealth of information to be found in the literature on oxidation behavior of WC composites. Experiments by Basu and Sarin [1] were conducted in pure oxygen or Ar-O mixtures, but most have been carried out in a muffle furnace with atmospheric air. Regardless of the medium, the fundamental oxidation reaction for tungsten carbide and oxygen, as clearly demonstrated by Kurlov and Gusev [2] in their rigorous investigative approach with four powders and evaluation of six reaction options, is as follows:

$\mathrm{WC}+(5 / 2) \mathrm{O}_{2}=\mathrm{WO}_{3}+\mathrm{CO}_{2}$.

These authors also commented on the strong exothermic effect of WC oxidation. Generation of $\mathrm{CO}_{2}$ is important in understanding why cracks and other defects develop, as the oxide grows on a tungsten/binder substrate.

The Pilling-Bedworth ratio (volume of oxide formed/ volume of metal consumed) for tungsten is 3.3 [3]. This ratio, being greater than two, indicates it will not be protective, and a large volume increase in the oxidized material 
is therefore anticipated. The highly porous nature of $\mathrm{WO}_{3}$, enhanced with fissures and other defects formed as $\mathrm{CO}_{2}$ (Eq 1) tries to escape, facilitates air access to the oxide/ metal reaction front. The result is negligible solid-state diffusion of $\mathrm{W}$ into the oxide, and with excess air supply by gaseous diffusion, the reaction front recedes uniformly into unreacted metal. This is described as an unreacted shrinking core oxidation model.

In a study by Aristizabal et al. [4], additions of $\mathrm{Ni}$ and $\mathrm{Cr}$ to the cemented Co-WC mix were investigated. They found that cermets with the highest tungstate/oxide $\left(\mathrm{WO}_{4}{ }^{2-} / \mathrm{WO}_{3}\right)$ ratios exhibited the lowest oxidation rate. The authors also demonstrated a linear oxidation correlation by plotting the fraction of material converted to oxide $(\alpha)$ versus time at temperatures from 700 to $850{ }^{\circ} \mathrm{C}$ :

$f(\alpha)=1-(1-\alpha)^{1 / 3}=k_{\text {surf }} \times t$,

where $f(\alpha)$ is a function dependent on the rate-controlling mechanism, $t=$ time and $k_{\text {surf }}=b k c / \rho_{m} \times A / V$, where $b=2 / 5$ [stoichiometric coefficient from (1)]; $k$ is the reaction rate constant; $c$ is oxygen concentration at the oxide/air interface; $A$ is external surface area; $V$ is sample volume; and $\rho_{m}$ is density of the cemented carbide. Activation energies reported for oxidation of 15 and $25 \%$ Co alloys were 190 and $269 \mathrm{~kJ} / \mathrm{mol}$, respectively. Voitovich et al. [5] calculated a value of $234.1 \mathrm{~kJ} / \mathrm{mol}$ for $15 \%$ Co material.

There is some controversy regarding whether or not WC oxidizes in air below $600{ }^{\circ} \mathrm{C}$. Humphrey-Baker and Lee [6] examined WC oxidation on their own and found that from RT-500 ${ }^{\circ} \mathrm{C}$, a bluish protective oxide of $\mathrm{WO}_{3}$ formed; above this temperature, a yellowish scale of $\mathrm{WO}_{3}$ was dominant. This scale was associated with cracks and displayed linear growth kinetics. Above $1000^{\circ} \mathrm{C}$, volatilization of $\mathrm{WO}_{3}$ leads to overall mass loss. Oxidation of WC was found to be faster than $\mathrm{W}$ by an order of magnitude in the temperature range $700-1000{ }^{\circ} \mathrm{C}$.

Data generated by Chen et al. [7] for reactions at $500{ }^{\circ} \mathrm{C}$ contradicted earlier results, which indicated oxidation of WC was easier than oxidation of Co. Using atomic force microscope (AFM) and electron probe X-ray micro-analyzer (EPMA) techniques, the authors demonstrated a parabolic behavior over $60 \mathrm{~min}$ for $\mathrm{Co}$, while oxidation of WC was negligible.

Although oxidation of Co can occur at temperatures as low as $200{ }^{\circ} \mathrm{C}$ [8], initiation of a reaction with WC occurs at about $500{ }^{\circ} \mathrm{C}$ (by thermal analysis). However, in a cemented carbide, the oxidation rate is much higher for Co and this results in selective attack of the binder phase, with little or no degrading influence on WC.

A more recent publication by Chen et al. [9] employing EPMA, grazing incidence X-ray diffraction (GIXRD) and $\mathrm{X}$-ray photoelectron spectroscopy (XPS) examined in detail the initial oxidation reactions for a WC-15\% Co cermet.
EMPA results distinguished three regions on a time/temperature plot:

1. Very slight oxidation.

2. Selective oxidation of the Co phase.

3. Simultaneous oxidation of Co and WC phases.

After 5-min air exposure, the three regions exhibit the following reactions:

Region (i): Below $450{ }^{\circ} \mathrm{C}$. Co and WC phases both slightly oxidized, due to physical and chemical adsorption of oxygen in air.

Region (ii): $450-570{ }^{\circ} \mathrm{C}$. Co becomes completely oxidized (EMPA). XPS data $\left(550^{\circ} \mathrm{C} / 5 \mathrm{~min}\right)$ revealed a thin layer of oxide over WC also. GIXRD showed this to be $\mathrm{CoWO}_{4}$ with a small fraction of $\mathrm{WO}_{3}$.

Region (iii): Above $570{ }^{\circ} \mathrm{C}$. Oxide scales mainly consist of $\mathrm{WO}_{3}$, with a small fraction of $\mathrm{CoWO}_{4}$.

Nucleation of the tungstate takes place exclusively on the cobalt phase. Chen lists several alternate reaction routes for tungstate formation:

- $\mathrm{Co}+\mathrm{W}+\mathrm{C}+3 \mathrm{O}_{2}=\mathrm{CoWO}_{4}+\mathrm{CO}_{2}$

Solid-solution reaction in Co phase

- $\mathrm{Co}+\mathrm{W}+2 \mathrm{O}_{2}=\mathrm{CoWO}_{4} \quad \mathrm{~W}$ diffusion from neighboring WC

- $\mathrm{Co}+\mathrm{WC}+3 \mathrm{O}_{2}=\mathrm{CoWO}_{4}+\mathrm{CO}_{2}$

Concurrent oxidation of $\mathrm{WC}$ and $\mathrm{Co}$

The range of analytical equipment used by Chen et al. has provided new insights and detail into the oxidation process of WC-Co cermets and will undoubtedly modify prior tenets. Earlier investigations have encompassed studies with Co contents ranging from 6 to $25 \%$. In general, the material was found to be stable and oxidation resistant up to about $600{ }^{\circ} \mathrm{C}$, but at higher temperatures serious degradation is initiated in the form of oxide growth, typified by oxide layer cracking, spalling, and substrate mechanical property degradation. Porosity present in the oxide, due to a large volumetric expansion associated with its formation and introduction of defects from generation of $\mathrm{CO}_{2}$ gas (formed as a by-product of oxidation), results in an "Unreacted Shrinking Core" model for the oxidation process over the range $600-850{ }^{\circ} \mathrm{C}$. In the case of a cobalt binder on its own, it was noted that while Co oxidizes sooner than $\mathrm{W}$, and faster than $\mathrm{Ni}$ or $\mathrm{Cr}$, this leads to a benefit in protection of WC due to an increase in tungstate formation. The greater the tungstate $/ \mathrm{WO}_{3}$ ratio, the greater is the oxidation resistance of WC. This is in large part due to the difference in morphologies of the two oxides; the tungstate is dense while $\mathrm{WO}_{3}$ is porous. 


\section{New Study: Annular Samples}

The present study examines weight gain and volumetric reactions on small WC- $6 \%$ Co cemented carbide annular samples after exposures to air in a muffle furnace for various time periods up to $10 \mathrm{~h}$ over the $500-1100{ }^{\circ} \mathrm{C}$ temperature range. This time/temperature range expands the scope of current literature data, which is concentrated on oxidation times up to $1 \mathrm{~h}$ and exposure temperatures from 550 to $850{ }^{\circ} \mathrm{C}$. Samples were loaded into a hot furnace (temperature recovery to $600{ }^{\circ} \mathrm{C}$ was a matter of a few minutes), thus minimizing oxidation reactions below the selected test temperature. The initial objective for extended time exposures was to understand why the bushing failed as a pressure control device in the field. However, early results at $700{ }^{\circ} \mathrm{C}$ indicated that important information regarding oxide growth mechanisms could be gained from expanding time/temperature exposures.

Unique oxide growth patterns were observed; large volumetric propagation was noted, perpendicular to all external surfaces up to $850^{\circ} \mathrm{C}$. In contrast, very little growth at any temperature took place on the inner cylindrical wall of the annulus. This could be explained by the generation of compressive forces on the oxide, effectively limiting the free ingress of air to the cermet surface. Although a detailed analysis was conducted on the ID of a sample exposed at $1000{ }^{\circ} \mathrm{C}$, energy-dispersive spectra (EDS) data did not indicate classic diffusion profiles for any of the principal elements. However, a good oxide/cermet bond was evident. This bond resisted annular separation from shrinkage during cooling down to ambient temperature.

The above hypothesis for constrained growth on the annular ID surface requires further validation. This could be accomplished by exposing samples of different inner diameters to $850{ }^{\circ} \mathrm{C}$, over a range of time exposures. For the compressive force hypothesis, there will clearly be a "critical diameter" at which oxide growth of the type observed on the OD will occur.

Plots of mass gain as a function of temperature indicate a linear relationship up to $850{ }^{\circ} \mathrm{C}$. A change in mechanism is apparent when temperatures reach $1000{ }^{\circ} \mathrm{C}$. This change, manifest as a departure from columnar growth, is thought to be related to an instability in oxide formation. It is known that $\mathrm{Co}_{3} \mathrm{O}_{4}$ breaks down at $950{ }^{\circ} \mathrm{C}$ :

$\mathrm{Co}_{3} \mathrm{O}_{4} \Rightarrow 3 \mathrm{CoO}+1 / 2 \mathrm{CO}_{2}$

Although not validated by analysis, it is hypothesized that an increase in $\mathrm{CoO}$ formation, whether by the above reaction or by direct formation, leads to larger defects and greater porosity. This allows greater exposure to furnace air and a near-linear oxidation rate. At $1100{ }^{\circ} \mathrm{C}$, there is another change, with oxidation rate over the first hour reducing to the same rate observed at $850{ }^{\circ} \mathrm{C}$. This is considered to be due to volatilization of $\mathrm{WO}_{3}$.

Analysis for carbon in the oxide layer, to determine completeness of reaction between WC and air, demonstrated the presence of larger amounts at lower temperatures, and anticipated decreases with temperature, and time at temperature. A very small amount of carbon (0.007 wt.\%) was found in the oxide of a sample exposed for $10 \mathrm{~h}$ at $1000{ }^{\circ} \mathrm{C}$. This indicates $99.9 \%$ of the original carbon in WC ( $6 \mathrm{wt} . \%)$ was reacted to form $\mathrm{WO}_{3}$ and $\mathrm{CO}_{2}$.

\section{Results}

\section{Sample Description and Mass Change Data}

The bushings are comprised of approximately $94 \%$ tungsten carbide (WC) particles in a binder of $6 \%$ cobalt $(\mathrm{Co})$, by weight. The WC particles are submicron, with an approximate size of $0.8 \mu \mathrm{m}$. The bushings have nominal dimensions of $8.9 \mathrm{~mm}$ outer diameter (OD) and $3.8 \mathrm{~mm}$ inner diameter (ID) and are $5.1 \mathrm{~mm}$ long. The WC/Co material is pressed and sintered into short tubes, which are then ground to outer dimensions and wire-EDM'd on the ID to customer specifications. The tube is then cut into multiple individual bushings, and the faces are machined to size and finish.

Macroviews and dimensions of a typical sample are presented in Fig. 1. Setup for thermal exposure in an air furnace is shown in Fig. 2. Post-exposure appearance of the samples is illustrated in Figs. 3, 4, 5, 6, 7, and 8. Mass change data for air exposures ranging from 1 to $10 \mathrm{~h}$ over the temperature range $500-1100{ }^{\circ} \mathrm{C}$ are recorded in Table 1 and plotted in Fig. 9.

Figure 9 exhibits initial linear tendencies for oxidation rate, but with increasing temperature and time, a change in oxidation mechanism is apparent. Measurements taken from Fig. 9a show that a mass change of $0.15 \mathrm{~g} / \mathrm{cm}^{2}$ can be obtained after $1 \mathrm{~h}$ at $950{ }^{\circ} \mathrm{C}$, or $3 \mathrm{~h}$ at $800{ }^{\circ} \mathrm{C}$, or $10 \mathrm{~h}$ at $780{ }^{\circ} \mathrm{C}$. The reduction in mass loss occurring at $1100{ }^{\circ} \mathrm{C}$, where a 1-h exposure (Fig. 9b) is apparently equivalent to mass loss experienced after $1 \mathrm{~h}$ at $850{ }^{\circ} \mathrm{C}$, is due to volatilization of $\mathrm{WO}_{3}$.

\section{Activation Energy Calculation}

A review of literature dealing with determination of rate constants from mass gain versus time data provided some useful information on optional approaches to the calculation $[10,11]$. Problems arise because of errors introduced by initial transient periods of more rapid oxide growth. However, in view of the very limited dataset available from the present study, the basic parabolic growth rate law was selected: 
Fig. 1 As-machined views of an annular WC-6\% Co sample. Sample dimensions: ID: $3.823 \mathrm{~mm}$; OD: $8.910 \mathrm{~mm}$; length: $5.140 \mathrm{~mm}$. Note: Small chamfer on major circumference edges
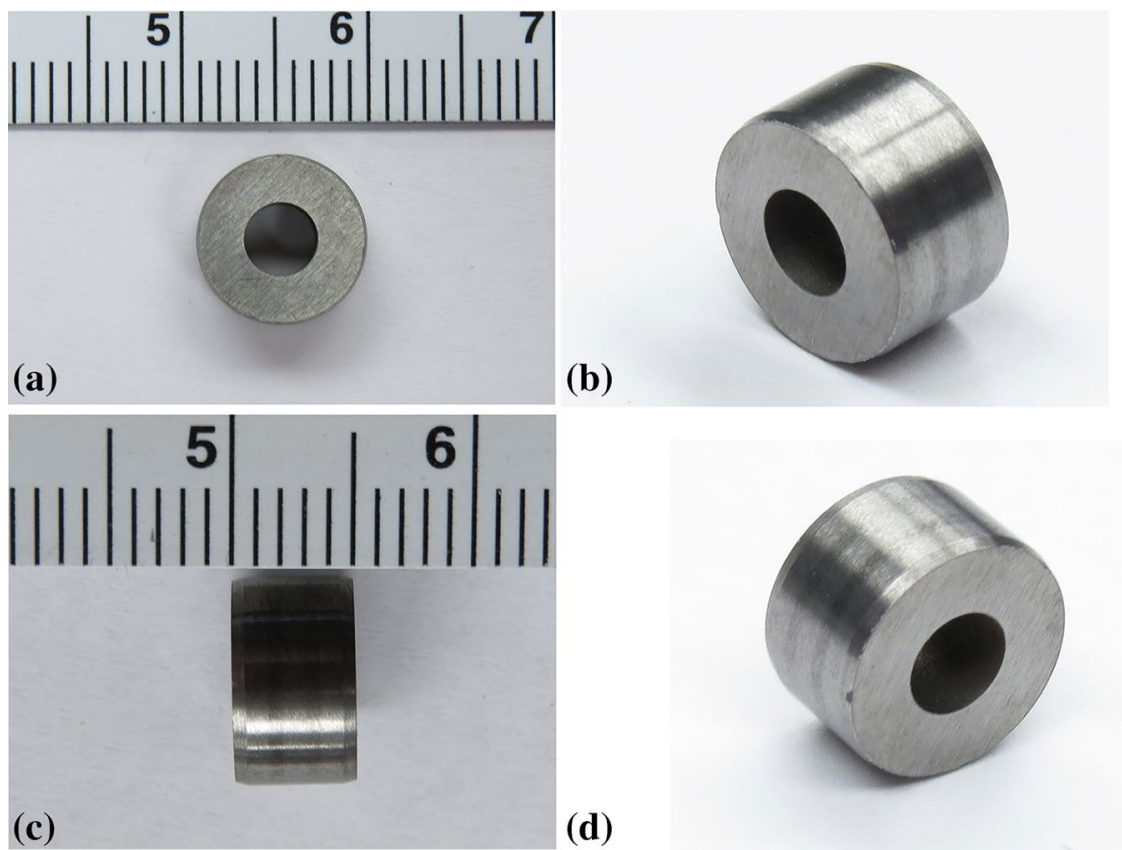

(d)
$\Delta m^{2}=k_{\mathrm{p}} t$

where $\Delta m$ is weight gain per unit area, $t$ is time, and $k_{\mathrm{p}}$ is the parabolic rate constant. The slope of a plot of $\Delta m^{2}$ versus $t$ is therefore equal to $k_{\mathrm{p}}$. From the Arrhenius relation, $k=A \exp ^{-Q / R T}$, we can write in linear form:

$\ln k_{p}=\ln A-Q / R T$,

where $A$ is a constant, $Q$ is the activation energy, $R$ is the gas constant, and $T$ is the absolute temperature. The slope of a plot of $\ln k_{\mathrm{p}}$ versus $1 / T$ will therefore be equal to $-Q / R$.

Mass change data presented in Fig. 9 illustrate a complete spectrum of change, from an essentially zero reaction rate at $500{ }^{\circ} \mathrm{C}$ for the WC component to volatilization of the $\mathrm{WO}_{3}$ oxide at $1100{ }^{\circ} \mathrm{C}$. In between these extremes, at 600,700 , and $850{ }^{\circ} \mathrm{C}$, it is reasonable to assume that a parabolic rate law describes the oxidation process. A plot of $\ln k_{\mathrm{p}}$ versus $1 / T$ is shown in Fig. 10.

The value of $Q$ calculated from the slope of the graph is $259 \mathrm{~kJ} / \mathrm{mol}$. This value is in good agreement with results obtained by Aristizabal (190 and $269 \mathrm{~kJ} / \mathrm{mol}$, for 15 and $25 \%$ Co alloys) [4] and Voitovich (234.1 kJ/mol for $15 \%$ Co material) [5].

It should be noted, however, that the annular geometry of samples used in the current experiments does lead to differences in oxide growth formation and to small errors in mass change per unit area calculations, due to the abnormal growth behavior on the small ID surface.

\section{Metallography}

The as-sintered microstructure was characterized at $1500 \times$ for alpha phase, grain size, and porosity according to the pertinent ASTM specifications. Typical microstructure at this magnification is presented in Fig. 11. The data, although acceptable, do not provide quantitative information for material with a submicron grain size. A more recent ISO standard (ISO 4499-2) uses the line intercept method for grain size and provides more definitive data.

\section{Scanning Electron Microscopy}

Initial characterization of the sintered WC- $6 \%$ Co structure, after oxidation in air at $700{ }^{\circ} \mathrm{C}$, was performed in an SEM. A linescan across the oxide/base metal interface on the ID surface of the annular sample was performed to document element interdiffusion features. These results are illustrated in Figs. 12 and 13.

A second SEM examination was conducted to evaluate the changes taking place at 850 and $1000^{\circ} \mathrm{C}$. Oxide composition was determined from the $850^{\circ} \mathrm{C}$ sample. Both ID and OD surfaces of the $1000{ }^{\circ} \mathrm{C}$ annular sample were evaluated. Results of this study are illustrated in Figs. 14, 15, 16, 17, 18,19 , and 20 . 

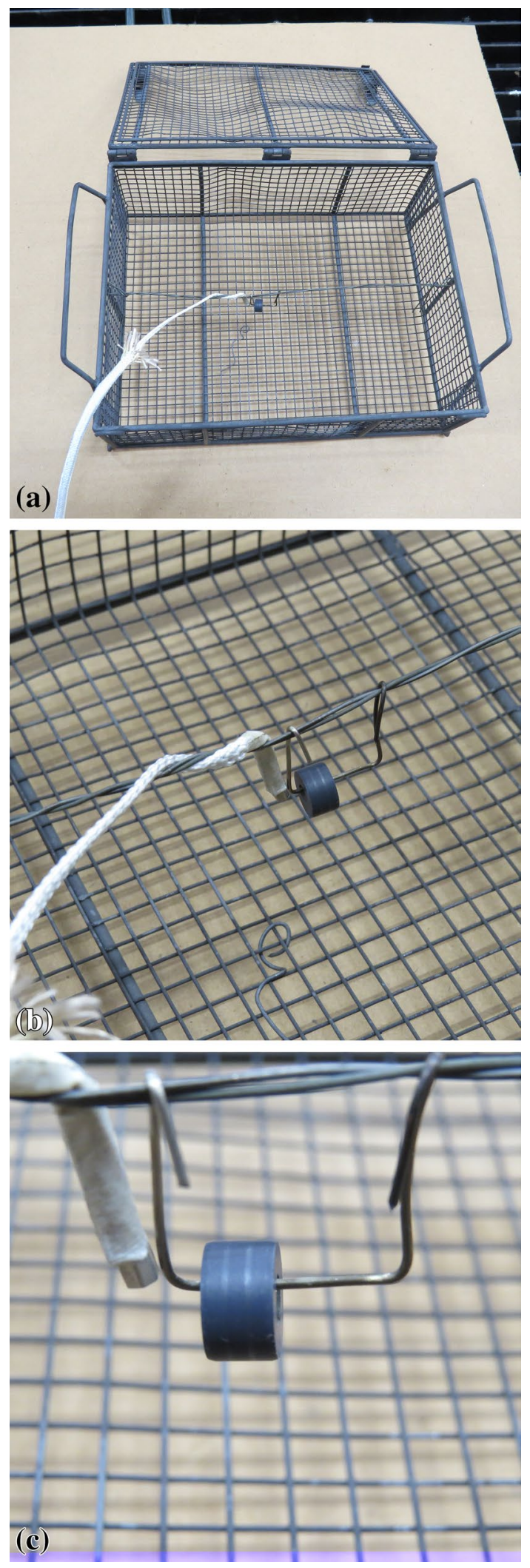

Fig. 2 Furnace loading setup, showing appearance after exposure at $600{ }^{\circ} \mathrm{C}$ for $1 \mathrm{~h}$

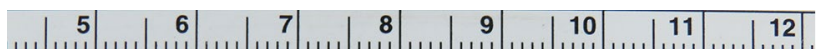
|||||||||||||||||||||||||||||||||||||||||||||||||||||||||||||||||||||||||||||||||||||| $\mid$
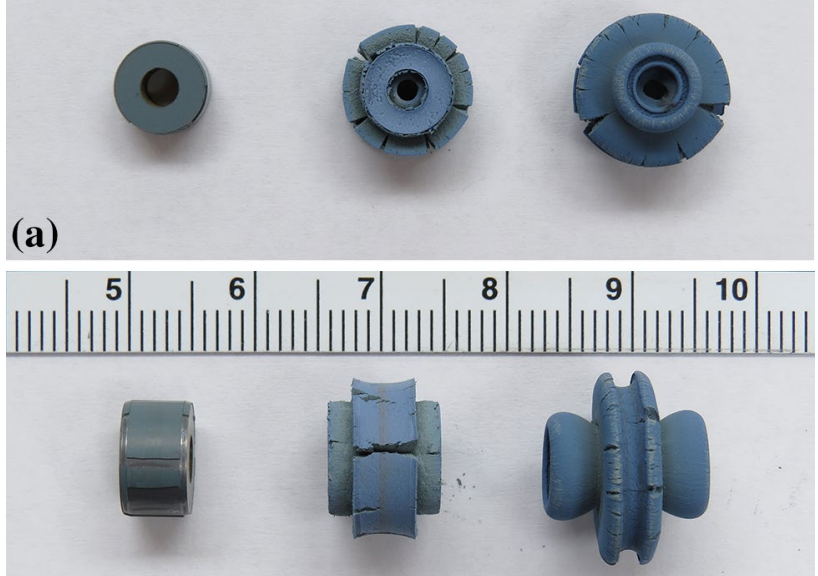

(b)

Fig. 3 Sample response to oxidation/ $1 \mathrm{~h}$ at $(\mathrm{L}-\mathrm{R}) 700,850$ and $1000{ }^{\circ} \mathrm{C}$

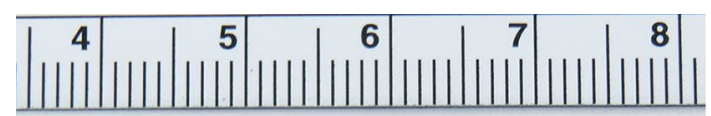

(a)
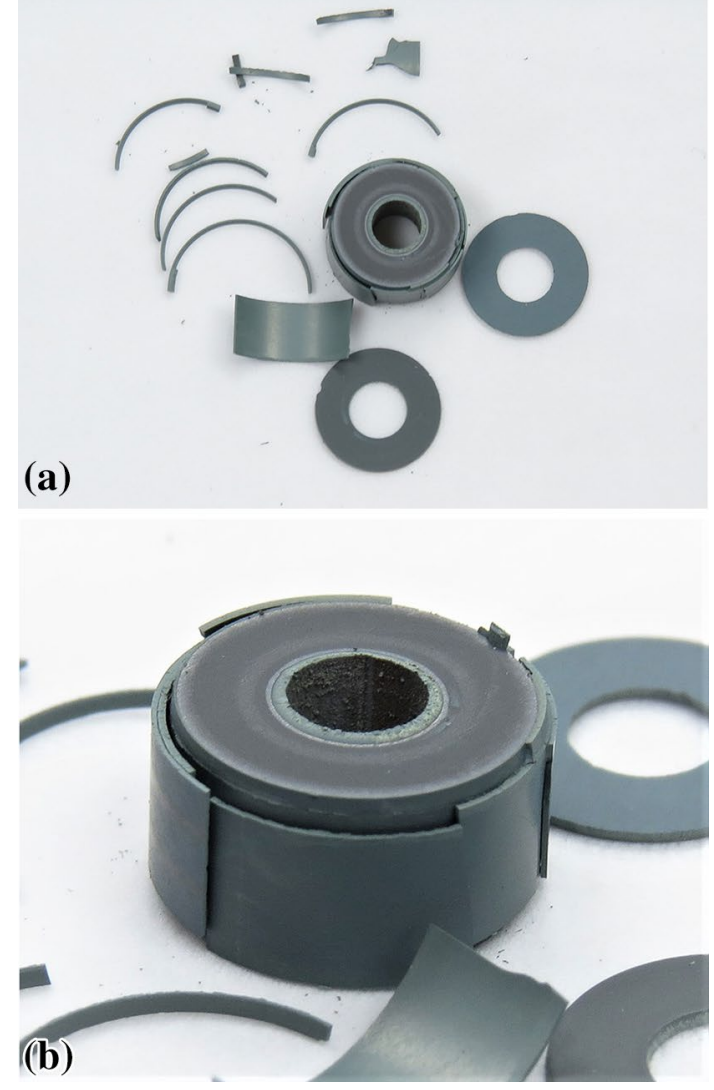

Fig. 4 Sample oxidized for $3 \mathrm{~h}$ at $700{ }^{\circ} \mathrm{C}$. Oxide layers have spalled off in uniform, thin sheets 

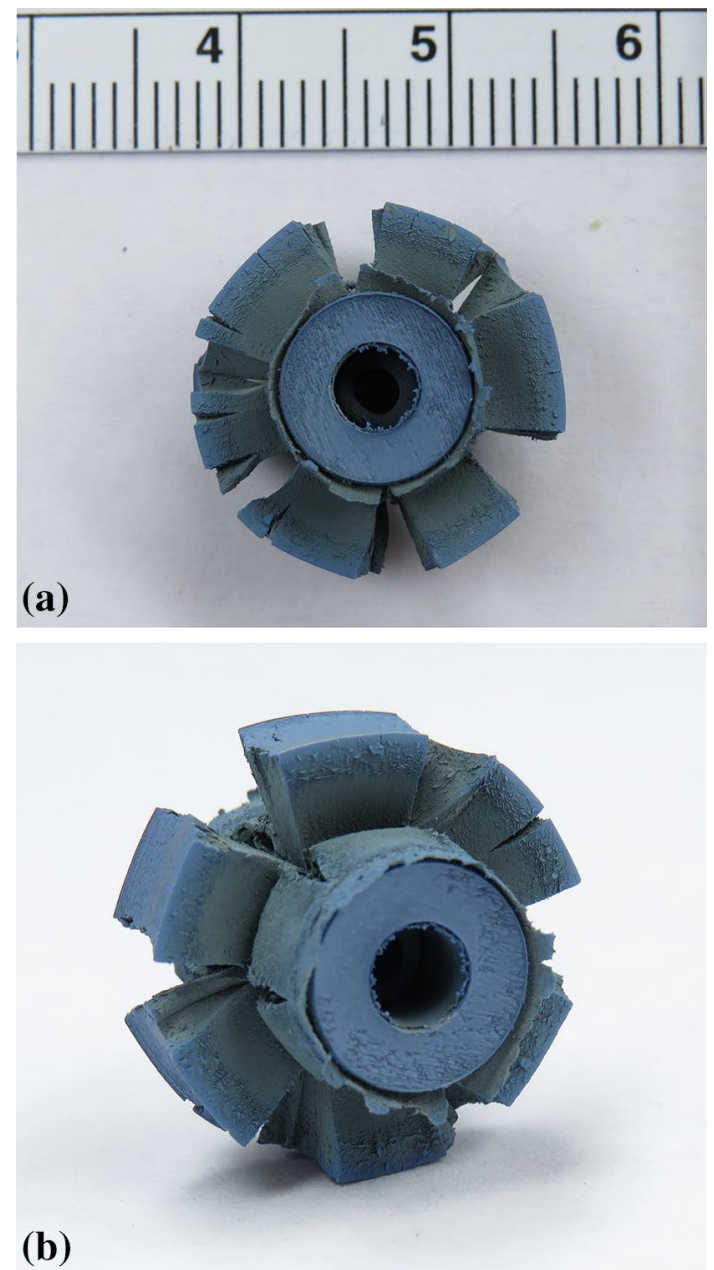

Fig. 5 Sample oxidized for $3 \mathrm{~h}$ at $850{ }^{\circ} \mathrm{C}$. Oxide layers have grown perpendicularly from all surfaces of the annulus

\section{WC/Co Bushing and Oxide Layer $\left(700^{\circ} \mathrm{C} / 3 \mathrm{~h}\right):$ ID Surface}

High-magnification views of the as-polished bushing surface are shown in Fig. 12a and b on a sample exposed at $700{ }^{\circ} \mathrm{C} / 3 \mathrm{~h}$. Base metal and oxide layer micrographs together with EDS analytical data are presented in Fig. 12c-f.

The EDS data taken from a relatively small area indicate the presence of $\sim 0.5 \% \mathrm{Cr}$ in the cermet. This may have been a deliberate addition to increase the volume of tungstate formed. Cobalt content in the substrate (Fig. 12f) appears to be slightly greater than the nominal $6 \%$, but this is due to localized variations in concentration.

The oxide layer formed at $700{ }^{\circ} \mathrm{C}$ has separated from the substrate during cooling. There is about a factor of three difference in CTE between the $94 \mathrm{~W}-6 \mathrm{Co}$ composite $\left(4.3 \times 10^{-6}\right)$ and $\mathrm{WO}_{3}\left(12 \times 10^{-6}\right)[12,13]$, so oxide growth on the ID of the annulus will take place under compressive stress, which will tend to restrict growth. But on cooling
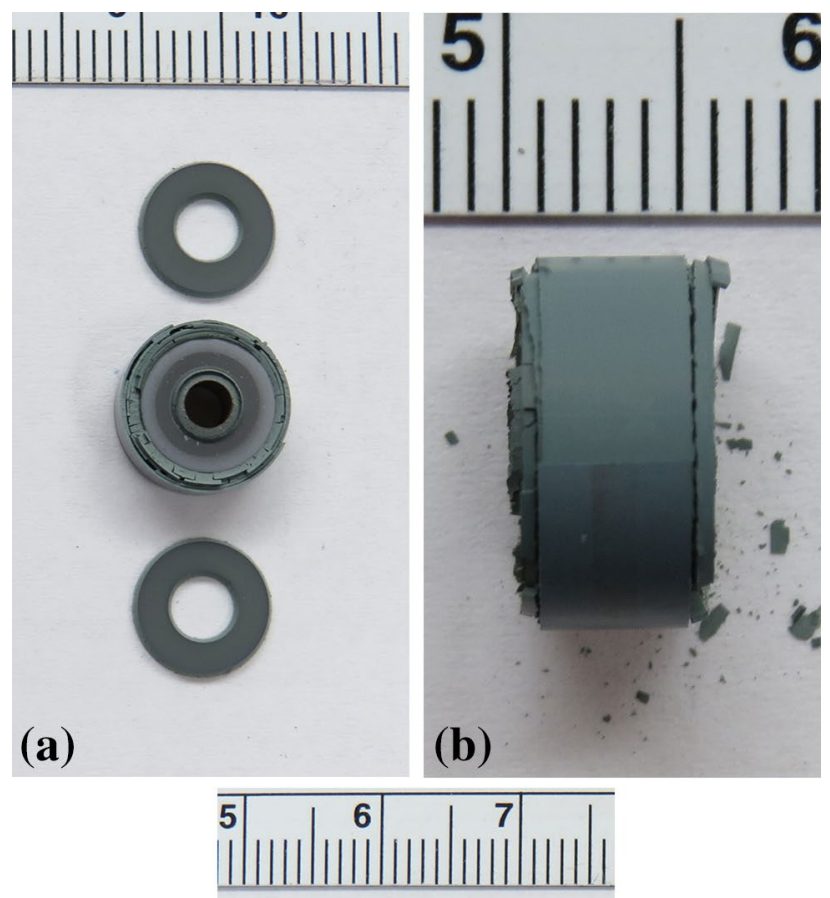

(c)

Fig. 6 State of oxidation after $10 \mathrm{~h}$ exposures at 700 and $850{ }^{\circ} \mathrm{C}$

down to ambient, the oxide layer will contract more rapidly and separate from the substrate. This situation can be observed in Fig. 12c.

Another tungsten carbide sample, oxidized at $700{ }^{\circ} \mathrm{C} / 3 \mathrm{~h}$, was polished, etched, and also examined in the SEM at high magnification. Figure 13 presents views of the microstructure using two different imaging modes, which reveal uniform features of fine tungsten carbide particles ( $\alpha$-phase) in a cobalt binder matrix ( $\beta$-phase). The secondary electron (SE) image, Fig. 13a, provides greater depth of field and finer detail. The backscattered electron (BSE) image, Fig. 13b, displays the WC particles as the bright phase and cobalt matrix as the darker phase. Images of the oxide layer are provided in Fig. 13c and d. Distinct phases are no longer present. The WC particles and cobalt matrix have reacted to form tungsten oxide $\left(\mathrm{WO}_{3}\right)$ and cobalt-tungstate $\left(\mathrm{CoWO}_{4}\right)$, according to the reactions shown in Eqs 1 and 3-5. 

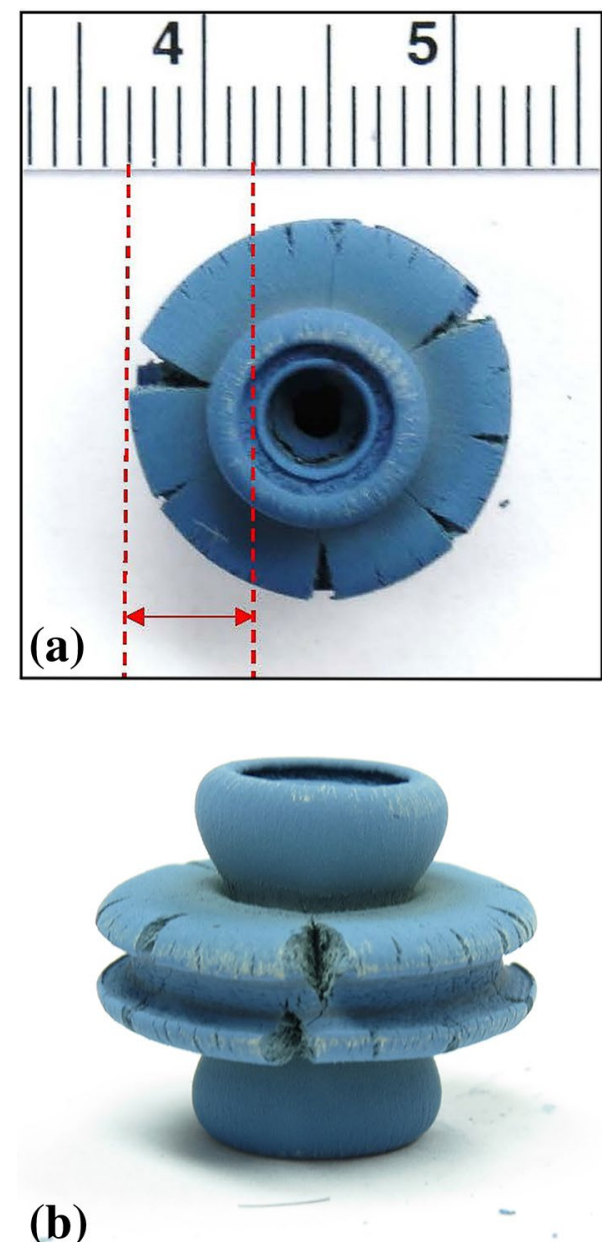

(b)

Fig. 7 Sample oxidized for $1 \mathrm{~h}$ at $1000{ }^{\circ} \mathrm{C}$. Oxide growth exhibits lateral expansion, no longer perpendicular from all surfaces of the annulus

The influence of oxygen on the WC/Co composite is significant. Exposure to air at $700{ }^{\circ} \mathrm{C} / 3 \mathrm{~h}$ has generated an oxide layer about $140 \mu \mathrm{m}$ thick on the ID surface. This layer has separated from the substrate on cooling. Oxidation of both the WC compound and the Co binder has occurred. In their university study, Basu and Sarin [1] found that although oxidation was almost negligible for a similar WC/6\% Co composite at $600{ }^{\circ} \mathrm{C}$, reaction with air increases rapidly with temperature. In agreement with other authors [2, 9], they determined that a mixture of two oxides is formed: tungsten oxide and cobalt-tungstate $\left(\mathrm{WO}_{3}\right.$ and $\left.\mathrm{CoWO}_{4}\right)$.

Figure 14 shows the location of a linescan, across the (shrinkage) gap from the ID oxide layer on the left, to the base material on the right. Tungsten and cobalt are clearly present in the oxide, but oxygen has not penetrated the WC- $6 \%$ Co substrate. There is no detectable diffusion gradient for oxygen. Separation has occurred, due to lack of any interdiffusion bond and a factor of three difference in coefficient of thermal expansion $\left(4.3 \times 10^{-6}\right.$ for $94 \mathrm{WC}-6 \mathrm{Co}$ versus $12 \times 10^{-6}$ for $\mathrm{WO}_{3}$ ).

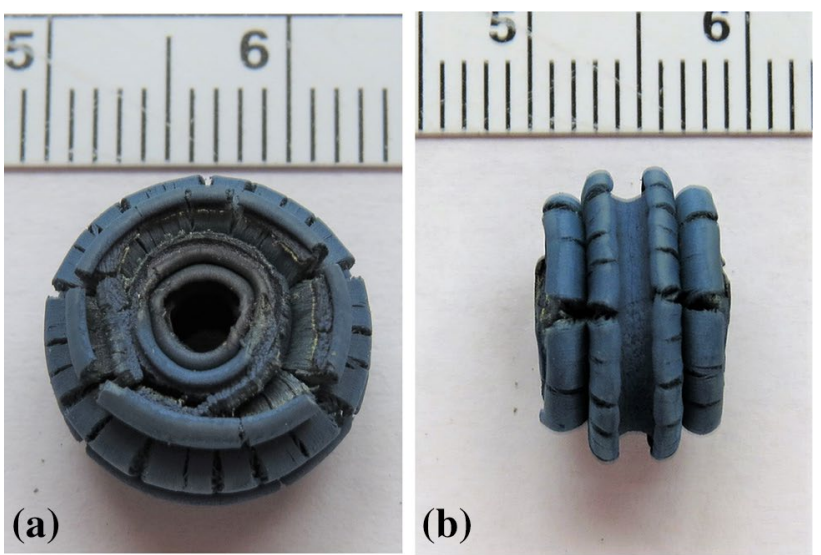

(c)

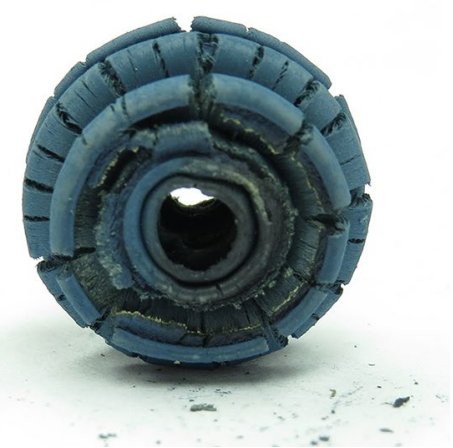

Fig. 8 Sample oxidized for $1 \mathrm{~h}$ at $1100{ }^{\circ} \mathrm{C}$. Reduced oxide growth, exhibiting multiple expansion fractures and accentuated rounding at all edges

Table 1 Mass change data for WC-6\% Co annular samples

\begin{tabular}{lrl}
\hline Temp. $\left({ }^{\circ} \mathrm{C}\right)$ & Time $(\mathrm{h})$ & Weight change $(\mathrm{g})$ \\
\hline 500 & 1 & +0.0008 \\
500 & 10 & +0.0011 \\
600 & 1 & +0.0046 \\
600 & 10 & +0 \\
700 & 1 & +0.0272 \\
700 & 3 & +0.0842 \\
700 & 10 & +0.1757 \\
850 & 1 & +0.3253 \\
850 & 3 & +0.6205 \\
850 & 10 & +0.7265 \\
1000 & 1 & +0.4825 \\
$* 1000$ & 3 & +0.7522 \\
1100 & 1 & +0.3344 \\
\hline
\end{tabular}

*Smaller hole; as-sintered

\section{Color Change in Oxide Layer $\left(850^{\circ} \mathrm{C} / 3 \mathrm{~h}\right)$}

EDS data were obtained from the outer darker blue band and the lower blue/gray region of an oxide sector removed from 
Fig. 9 Plots of mass gain as a function of (a) temperature and (b) time
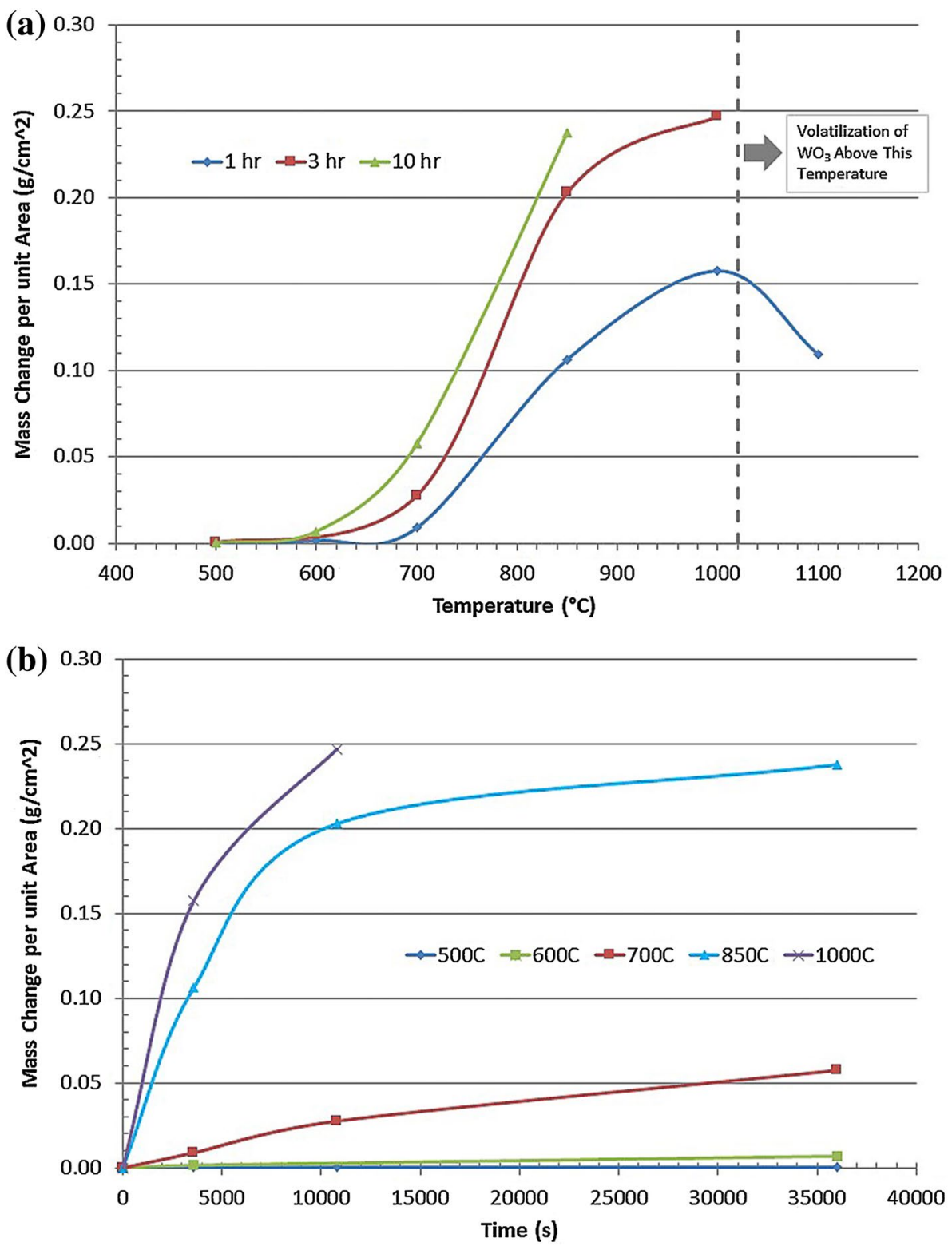

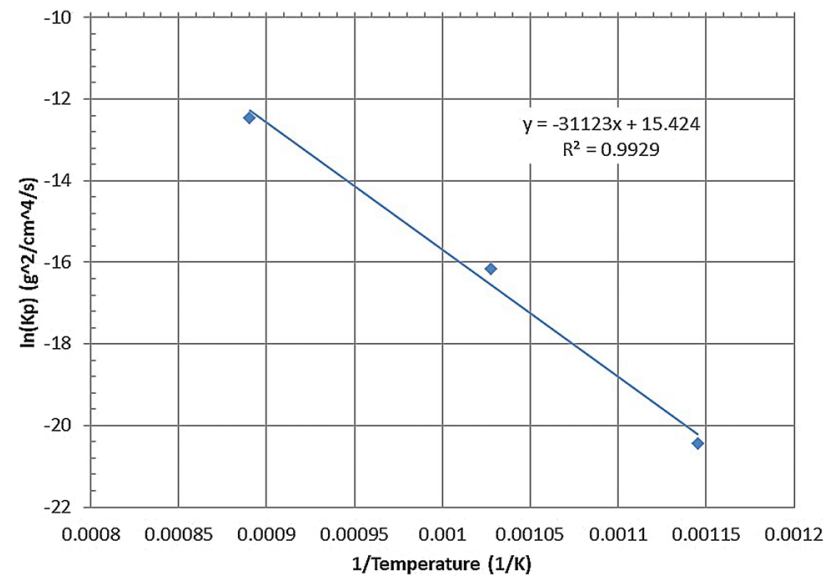

Fig. 10 Arrhenius plot of parabolic rate constant the OD surface of a sample heated at $850{ }^{\circ} \mathrm{C} / 3 \mathrm{~h}$. Results of this analysis are compared in Fig. 15. The striking color change illustrated in Fig. 6 appears to be due to an enrichment of Co in the first oxide layers to form.

This finding points to a change in oxidation of the Co and W phases after initial oxide formation. Part of the Co enrichment may be due to oxidation occurring during the ramp-up to exposure temperature, where it is known that the cobalttungstate compound forms at the surface on the $\beta$-phase, in preference to $\mathrm{WO}_{3}$. As noted earlier, this period of heat-up to $850{ }^{\circ} \mathrm{C}$ is a matter of $\sim 20 \min \left(\sim 500-850{ }^{\circ} \mathrm{C}\right)$; it encompasses the temperature range in which tungstate formation on the binder phase dominates. Once at $850{ }^{\circ} \mathrm{C}$, however, formation of $\mathrm{WO}_{3}$ will overwhelm the oxidation process. 


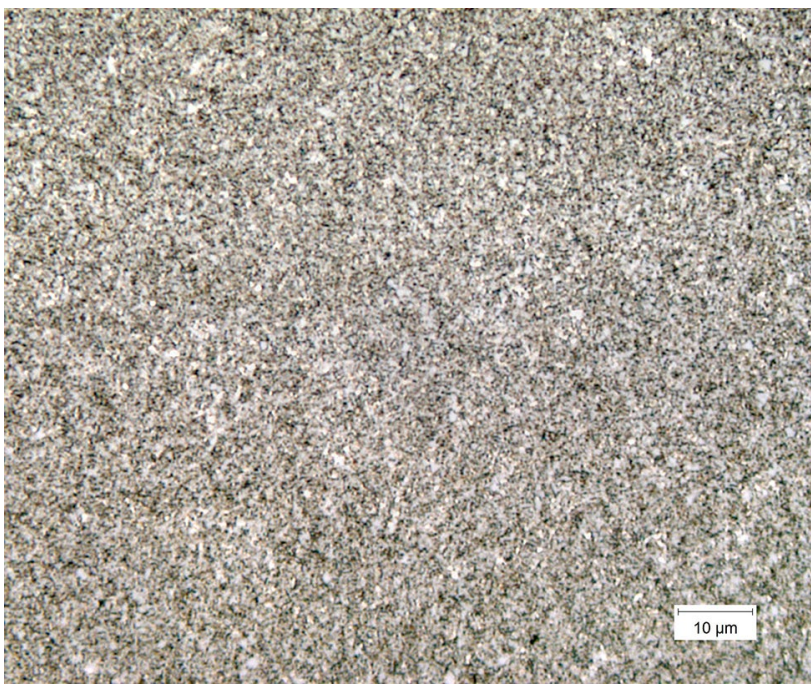

Fig. 11 Metallographic evaluation of WC-Co binder microstructure: $\alpha$-phase: fine (Per ASTM B657-11). Grain size: Type 6F (per ASTM B390-92). Carbide porosity: A00, B00, C00, per ASTM B276-05 (measured in the unetched condition). 1500X (A clearer view of the very small grains in the bushing material is shown in Fig. 13.)

\section{WC/Co Bushing $\left(1000^{\circ} \mathrm{C} / 1 \mathrm{~h}\right):$ Oxide Growth Interface and Surface Reactions}

Geometry of the oxide formed at $1000{ }^{\circ} \mathrm{C}$ exhibited a departure from the strong columnar character of oxide growth observed up to $850^{\circ} \mathrm{C}$. Examination of an area on the OD, following removal of an oxide sector, led to observation of an unexpected growth pattern at the oxide/substrate interface. This pattern is illustrated in Fig. 16.

Breakaway of the sector demonstrated the absence of inward diffusion beyond the reaction surface. Large areas of unreacted metal surface are shown in Fig. 16c and d. Prominent spiral structures cover the flat OD surface. Smaller spirals are neatly packed along the chamfered edge. One of the larger spirals was examined and mapped in the SEM. Images are presented in Fig. 17. Carbon is a dominant feature on these growth spirals. This finding is consistent with the major chemical reaction in oxide formation at this temperature, which involves breakdown of WC to form $\mathrm{WO}_{3}$. The driving force behind formation of the growth spiral geometry at the reaction surface is not known.

\section{WC/Co Bushing and Oxide Layer $\left(1000^{\circ} \mathrm{C} / 1 \mathrm{~h}\right):$ ID and OD Surfaces}

The ID and OD reaction surfaces of the bushing were examined on a mounted sample. Most of the OD oxide growth was removed before preparation, but linescan analysis focused on surface areas where adherent oxide remnants remained. The ID oxide layer was intact and not visibly separated from the substrate. Light microscope and SEM images of the two surfaces are shown in Fig. 18. Linescan data obtained across the oxide interfaces are presented in Figs. 19 and 20, and EDS data in Table 2. Findings and observations are reviewed in Discussion section. Weight\% EDS data in Table 2(a) confirm the overall composition of this material as $6 \%$ Co with a $0.5 \%$ addition of $\mathrm{Cr}$.

\section{Unreacted Carbon in the Oxide Layer}

Three samples were analyzed for carbon remaining in the oxide. A range of time/temperature exposures was selected for this analysis. Data are presented in Table 3.

These oxidation exposures have reduced the original carbon content of $\sim 6 \mathrm{wt} . \%$ to a very small fraction of the starting value. The change indicates almost complete conversion of carbon tied up as WC in the cermet to $\mathrm{CO}_{2}$. Generation of this gas contributes to defect formation in the oxide layer.

\section{Discussion}

The annular sample geometry produced some interesting and unexpected oxide growth behavior that would not have been observed on planar coupons. Each topic associated with this study is discussed in turn, and some important conclusions are drawn from data obtained and observations made.

\section{Mass Change Data and Growth Geometry}

The annular sample geometry presents challenges for a detailed quantitative analysis of mass change. Our observations regarding OD surface oxidation of the annulus do, however, support an unreacted shrinking core model, at least up to $850{ }^{\circ} \mathrm{C}$. This requires a non-porous solid reactant, which can be claimed from integrity of the highmagnification SEM microstructures. The oxide layer is porous and contains cracks and fissures, produced by the volume change in transforming $\mathrm{WC}$ into $\mathrm{WO}_{3}$, generating a factor of three difference in CTE in addition to formation of carbon dioxide. With the annular geometry, there are clearly additional stresses placed on the OD surface oxide, from radial growth on a convex surface, when compared to growth on the planar surface of a coupon.

Figures 3, 4, 5, 6, 7, 8, and 9 present changes in oxide growth geometry with temperature. One important feature of these changes is behavior of growth on the ID surface. Oxide formation is thought to be suppressed by generation 

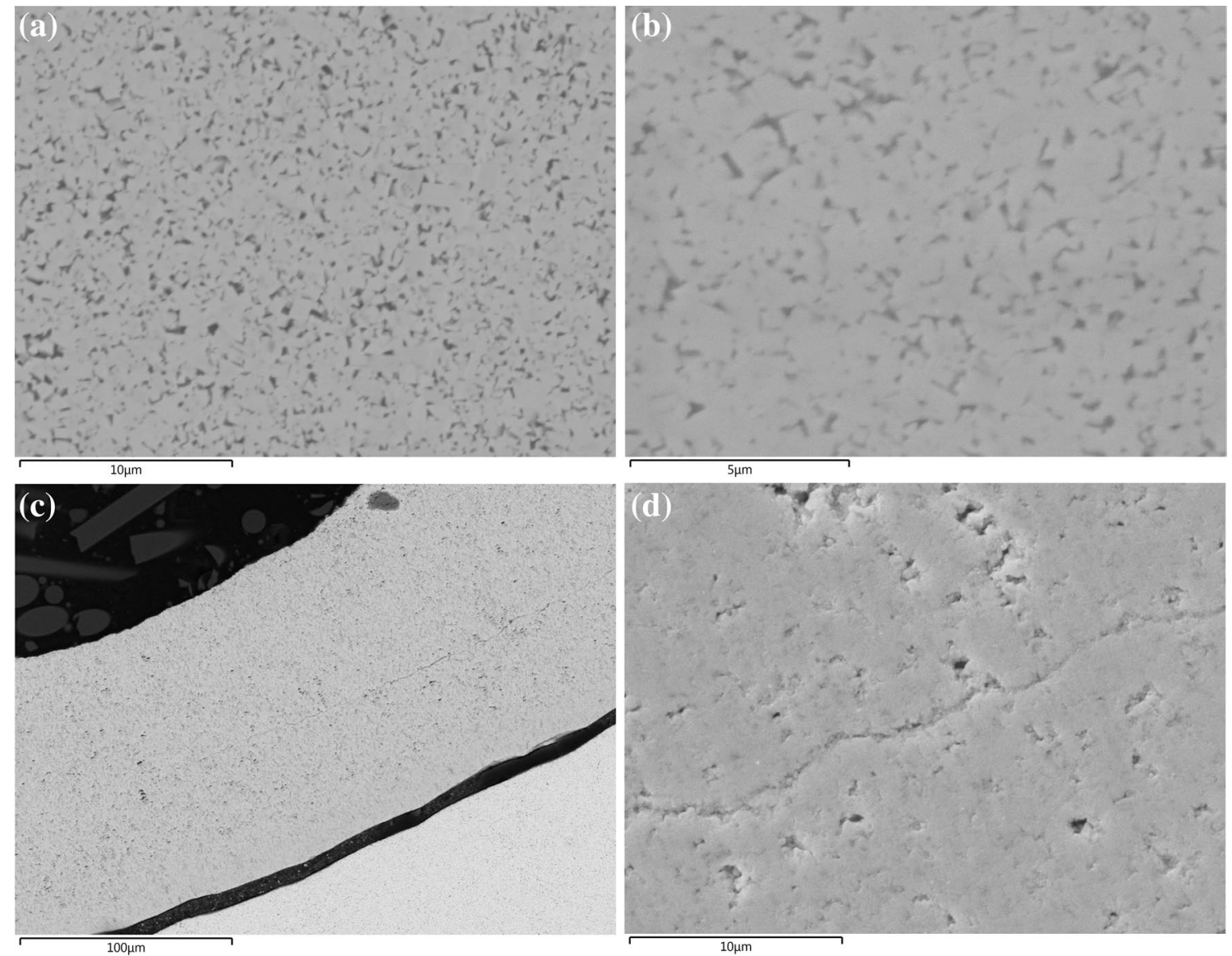

(e)

(f)

\begin{tabular}{|c|c|c|}
\hline Element & Weight \% & Atomic \% \\
\hline $\mathrm{C}$ & 7.47 & 28.13 \\
\hline $\mathrm{O}$ & 17.98 & 50.84 \\
\hline $\mathrm{Co}$ & 5.13 & 3.94 \\
\hline $\mathrm{W}$ & 69.42 & 17.09 \\
\hline Total: & 100.00 & 100.00 \\
\hline
\end{tabular}

\begin{tabular}{|c|c|c|}
\hline Element & Weight \% & Atomic \% \\
\hline $\mathrm{C}$ & 4.24 & 36.57 \\
\hline $\mathrm{Cr}$ & 0.47 & 0.93 \\
\hline $\mathrm{Co}$ & 7.39 & 12.98 \\
\hline $\mathrm{W}$ & 87.90 & 49.52 \\
\hline Total: & 100.00 & 100.00 \\
\hline
\end{tabular}

Fig. 12 (a, b) As-polished view of WC-6\% Co composite structure, exposed $700{ }^{\circ} \mathrm{C} / 3 \mathrm{~h}$ : Co binder is the dark phase. (c-f) Comparison of base composite and oxide layer on ID surface. Note: carbon values are qualitative only

of compressive stresses in the oxide layer, which tend to close fissures, isolate pores, and so restrict free airflow to the reacting metal surface. On the ID of the annulus, the oxide becomes more protective and the shrinking core oxidation process is shut down. The illustrations over the $700-1100{ }^{\circ} \mathrm{C}$ temperature range exhibit limited oxide formation on the ID of the annulus samples, as compared to that found on the OD surface.

Oxide growth geometry on the OD surfaces changes with increasing exposure temperature. After $1 \mathrm{~h}$ at $700{ }^{\circ} \mathrm{C}$, a thin, rigid layer peels or spalls off exposed surfaces, including perfect "washer" shapes from the sides of the annulus. Even the chamfered edges generate their own thin rings of oxide. At this temperature, and at $850{ }^{\circ} \mathrm{C}$, this geometrically structured growth, perpendicular from all OD surfaces, continues. Basu and Sarin [1] explain this behavior by noting the tendency for $\mathrm{WO}_{3}$ to grow in a columnar mode, thus restricting lateral expansion. However, there is a departure from this form at $1000{ }^{\circ} \mathrm{C}$. Oxide formation is no longer unidirectional, and for the annulus, this resulted in growth of a conically shaped oxide formation from the planar ends and formation of a "bobbin" geometry from the curved OD surface of the annulus. 

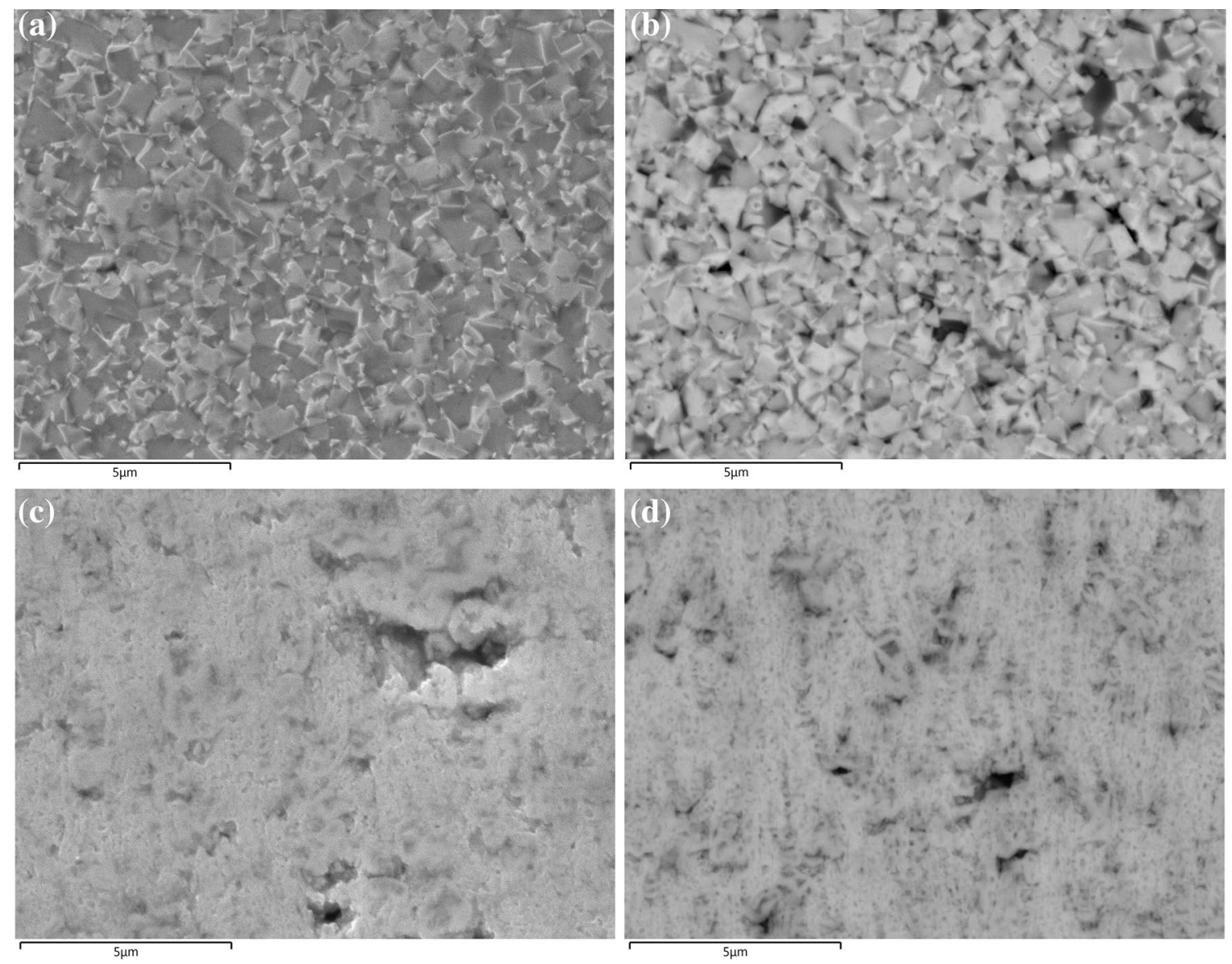

Fig. 13 (a, b) SEM images of the WC/Co structure and (c, d) the oxide layer, formed after exposure in an air furnace @ $700{ }^{\circ} \mathrm{C} / 3 \mathrm{~h}$. Sample etched in $10 \% \mathrm{NaOH}$ in water mixed $1: 1$ with $10 \% \mathrm{~K}_{3} \mathrm{Fe}(\mathrm{CN})_{6}$ in water

This change in oxidation mode may be related to a change in oxides present. Below $800{ }^{\circ} \mathrm{C}, \mathrm{WO}_{3}$ and $\mathrm{CoWO}_{4}$ are the only oxides formed [1,2]. At $850{ }^{\circ} \mathrm{C}$, columnar-controlled growth is still evident (Figs. 3 and 5). At higher temperatures, oxidation reactions in air may produce cobalto-cobaltic oxide $\left(\mathrm{Co}_{3} \mathrm{O}_{4}\right)$. However, at $\sim 950{ }^{\circ} \mathrm{C}$, this compound breaks down into $\mathrm{CoO}$ and $\mathrm{O}_{2}$. The complexities introduced by these potential changes in oxide compound formation are significant. Together with an increased probability of direct $\mathrm{CoO}$ formation, they may account for the loss of columnar growth control and concomitant shape conformance to the underlying metal surface. An increase in $\mathrm{CO}_{2}$ will exacerbate porosity and defects and so allow more open access of air to the oxidation reaction zone. In addition, freedom for lateral oxide growth may also explain the significant increase in oxidation rate.

\section{Scanning Electron Microscopy}

Selective SEM studies of the sample set were conducted. Figure 13 , taken at $20 \mathrm{kX}$, depicts the very small grain size and the presence of small, angular WC particles. EDS data (Fig. 12) support the composition as $94 \% \mathrm{~W}, 6 \% \mathrm{Co}$, but with an apparent addition of $0.5 \% \mathrm{Cr}$.

The oxide formed at $700{ }^{\circ} \mathrm{C}$ is porous. Although the ID oxide separated from the cermet substrate after a 3-h exposure to air at $700{ }^{\circ} \mathrm{C}$ (Fig. 12), linescan data presented in Fig. 14 indicate no evidence for oxygen diffusion into the base material. Oxide formation and growth take place on the metal surface by allowing air to flood the oxide/cermet interface via linked pores and other defects. It is only during cooling down that oxide breakaway occurs at the reaction interface, due to the large difference in CTE. At this temperature, there is not a great deal of difference in oxide growth rate on the ID and OD after a 3-h exposure, so that oxide layers formed are of a similar thickness. These results support the unreacted shrinking core model for oxidation at $700{ }^{\circ} \mathrm{C}$.

All oxidized samples, to some degree, show a darkblue outer band within the OD oxidized layer. This is exhibited in very clear form by Sample T507-C, exposed for $3 \mathrm{~h} @ 850{ }^{\circ} \mathrm{C}$, (Fig. 5). A sector of this sample was removed for SEM evaluation. EDS data in Fig. 15 show 


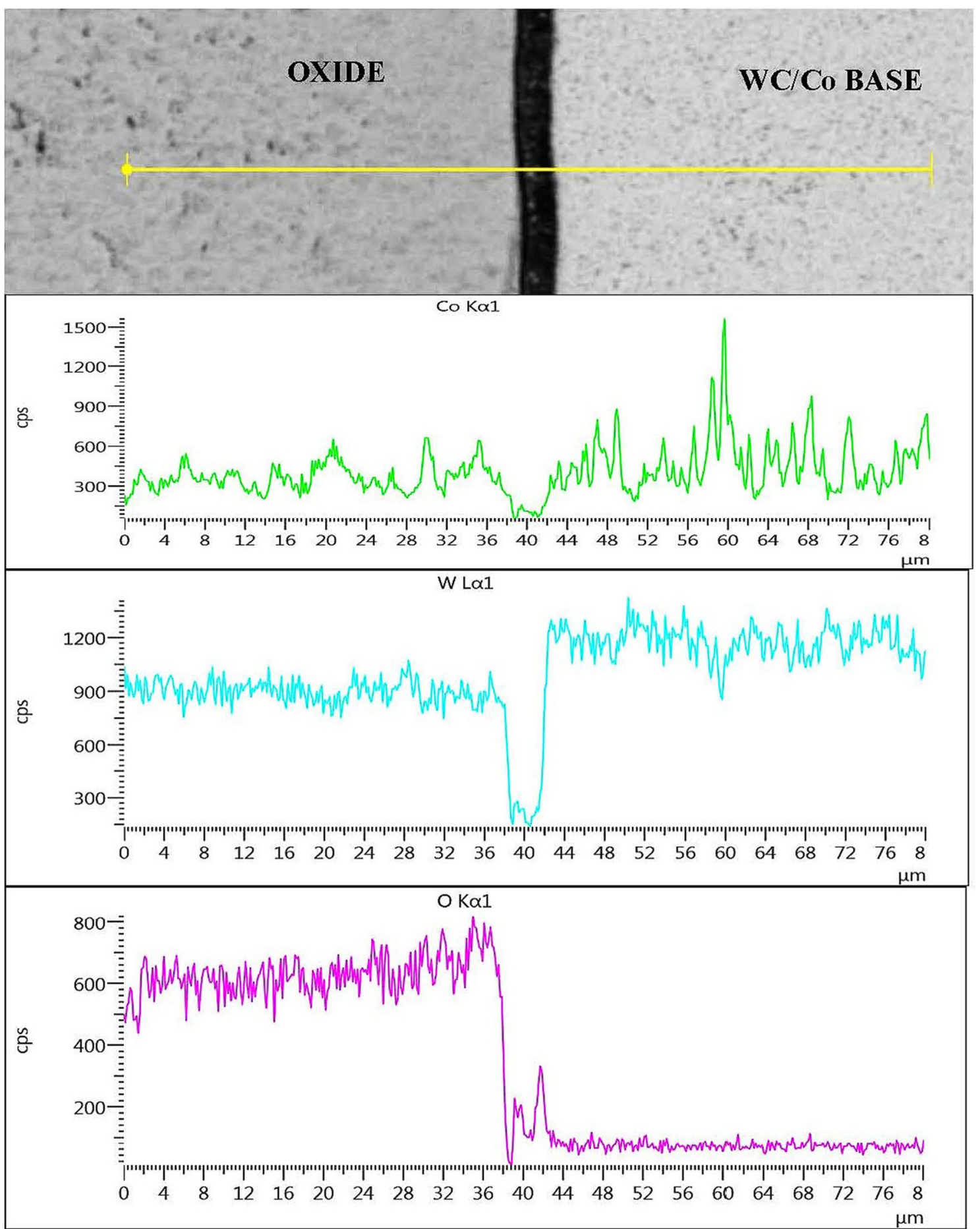

Fig. 14 Linescans showing change in chemistry from ID oxide layer to base material. Sample exposed at $700{ }^{\circ} \mathrm{C} / 3 \mathrm{~h}$

that concentration of Co in this outer region of the oxide (i.e., zone of oxide that formed first) contains about twice the level of Co as later (inner) oxide growth. It was also noted that:
- The blue coloration was confined to the outer surfaces of all samples.

- All blue coloration was removed after exposure in the SEM. 


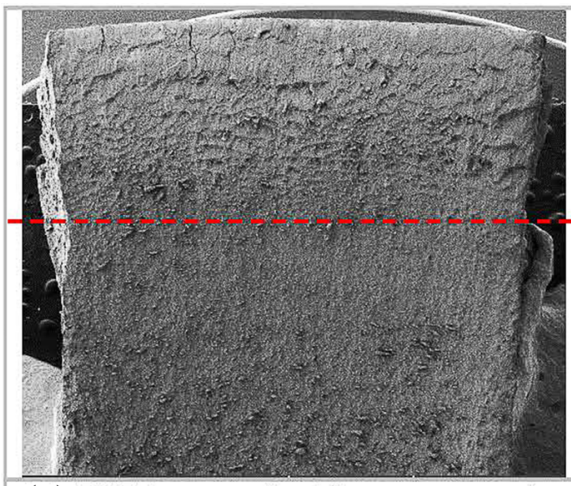

(a) BSE image of oxide sector sample. 50X

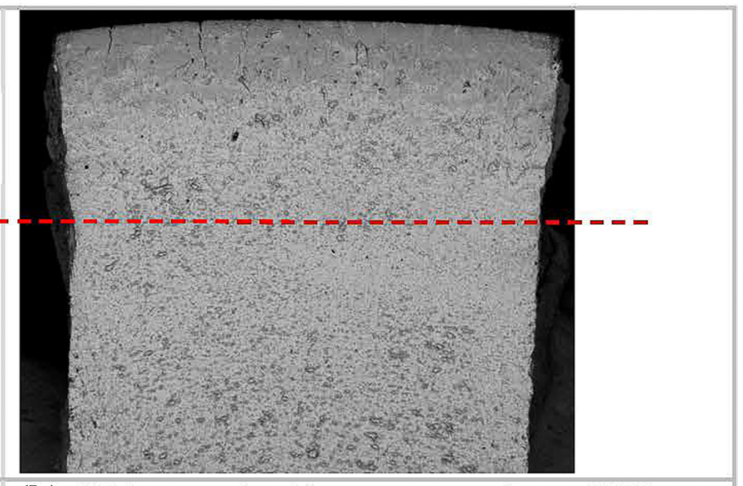

(b) SE image of oxide sector sample.
$50 \mathrm{X}$

\begin{tabular}{||c|c|c|}
\hline Element & Weight \% & Atomic \% \\
\hline $\mathrm{O}$ & 27.55 & 75.75 \\
\hline $\mathrm{Co}$ & 13.63 & 10.17 \\
\hline $\mathrm{W}$ & 58.82 & 14.07 \\
\hline Total: & 100.00 & 100.00 \\
\hline
\end{tabular}

(c) EDS data from dark blue outer band.

\begin{tabular}{|c|c|c|}
\hline Element & Weight \% & Atomic \% \\
\hline $\mathrm{O}$ & 22.89 & 74.20 \\
\hline $\mathrm{Co}$ & 6.76 & 5.95 \\
\hline $\mathrm{W}$ & 70.35 & 19.84 \\
\hline Total: & 100.00 & 100.00 \\
\hline
\end{tabular}

(d) EDS data from blue/grey inner region.

Fig. 15 Comparison of EDS data obtained from the outer dark-blue band in the oxide layer and the inner blue/gray core. Exposed at $850{ }^{\circ} \mathrm{C} / 3 \mathrm{~h}$ (Color figure online)

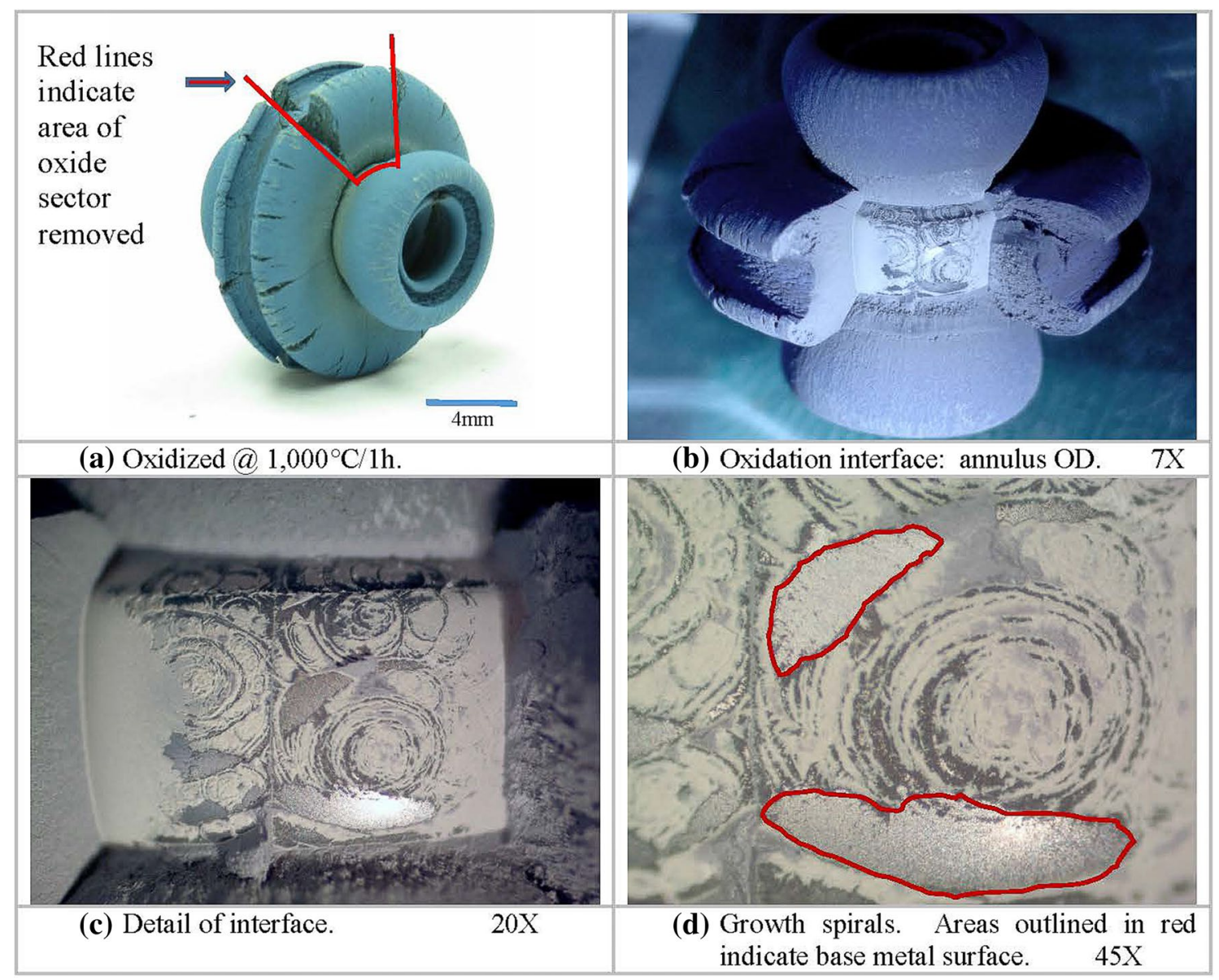

Fig. 16 Growth spiral development at oxide/WC-6Co composite interface after air exposure at $1000{ }^{\circ} \mathrm{C} / 1 \mathrm{~h}$ 

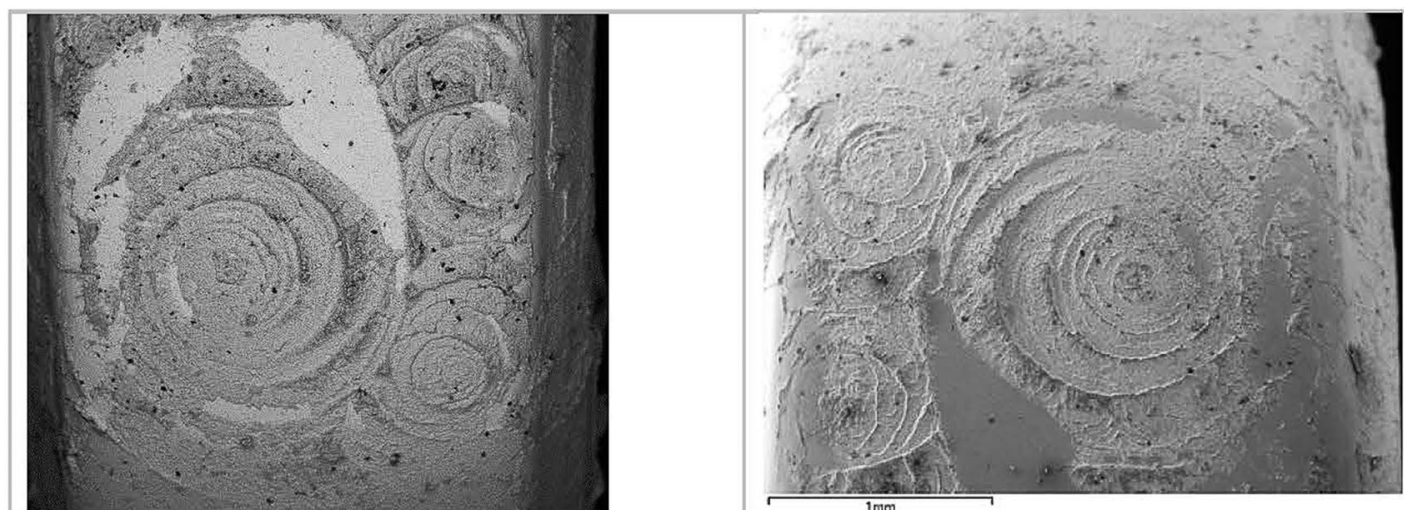

(a) Growth spirals on annulus OD surface. $75 \mathrm{X}$

(b) SE image of map area.

$100 X$
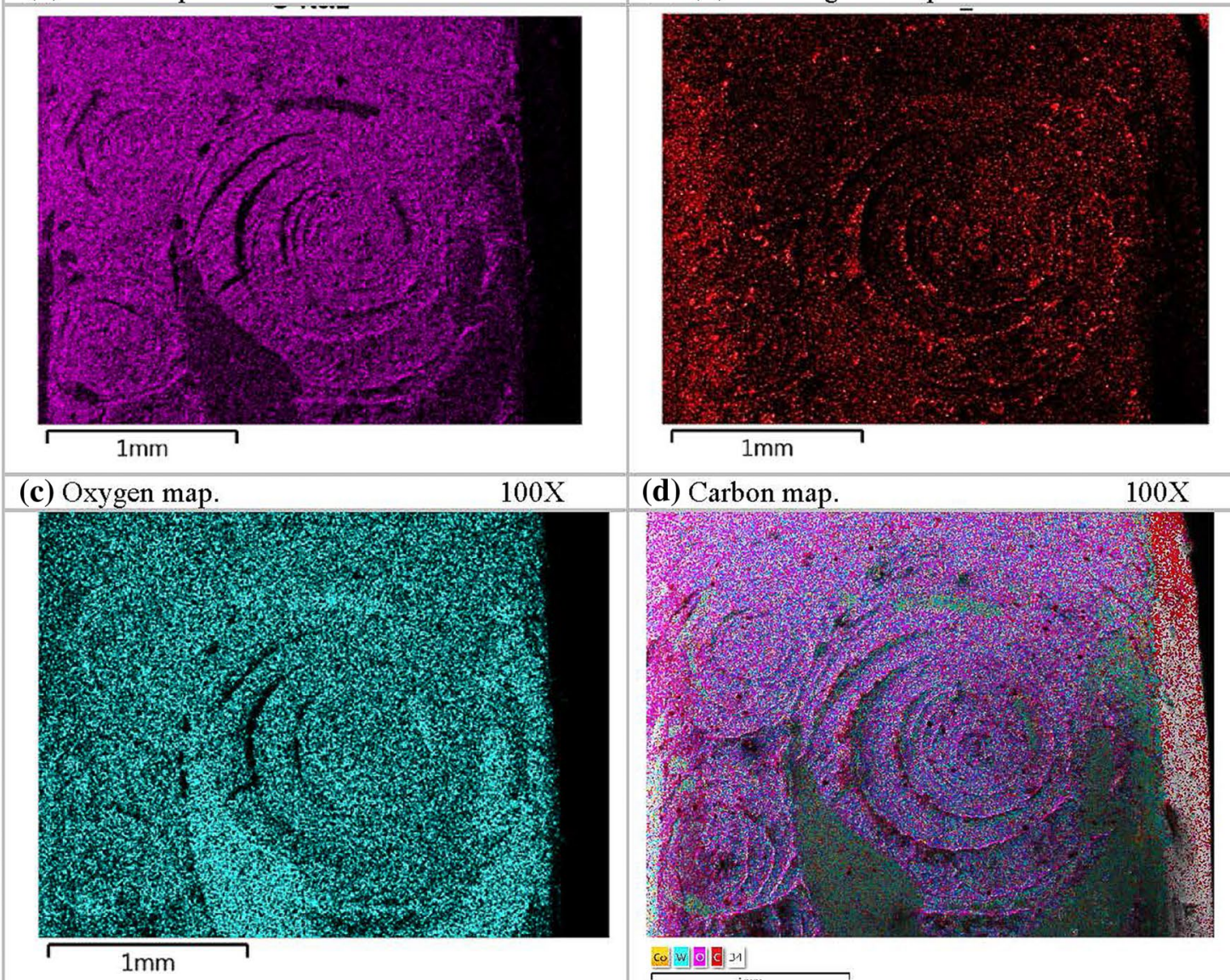

(e) Tungsten map (Co map is similar). 100X

$100 \mathrm{X}$

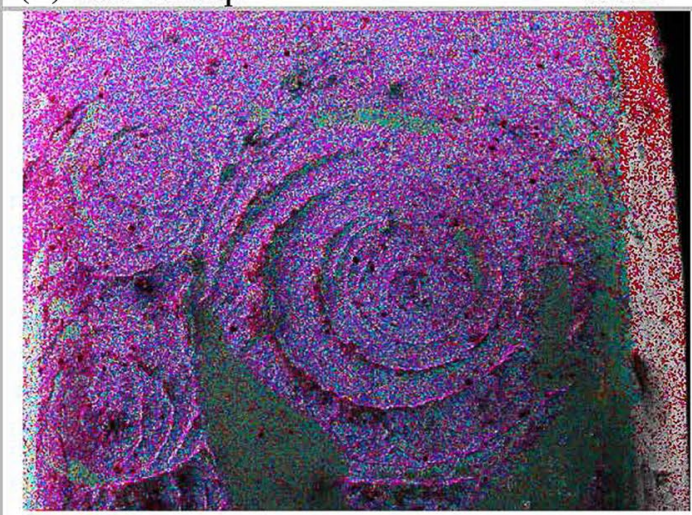

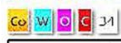

(f) Map overlay of W, Co, C and O. 100X

Fig. 17 Element mapping on oxide growth spiral. Note distinct carbon contribution to oxidation reaction on spiral peak. Exposed at $1000{ }^{\circ} \mathrm{C} / 1 \mathrm{~h}$

It was concluded that the samples picked up moisture when exposed to air after removal from the furnace and formed a dark-blue compound $\left[\mathrm{Co}\left(\mathrm{H}_{2} \mathrm{O}\right)_{4}(\mathrm{OH})_{2}\right]$, predominantly on exposed surfaces in the area with higher Co content. Exposure in the SEM was sufficient to dehydrate this compound and remove the coloration. The reason why initial oxide formation is rich in Co requires further investigation.
The bushing sample oxidized at $1000{ }^{\circ} \mathrm{C}$ was examined in detail, (Figs. 16, 17, 18, 19, and 20). A sector of the bobbinoxide structure was carefully broken from the substrate for evaluation in the SEM. Its removal revealed a spiral pattern on the cermet surface, at the growth front of the oxide layer. The carbon map (Fig. 17d) clearly indicates oxidation of $\mathrm{WC}$ is a dominant factor in spiral formation. Distribution 

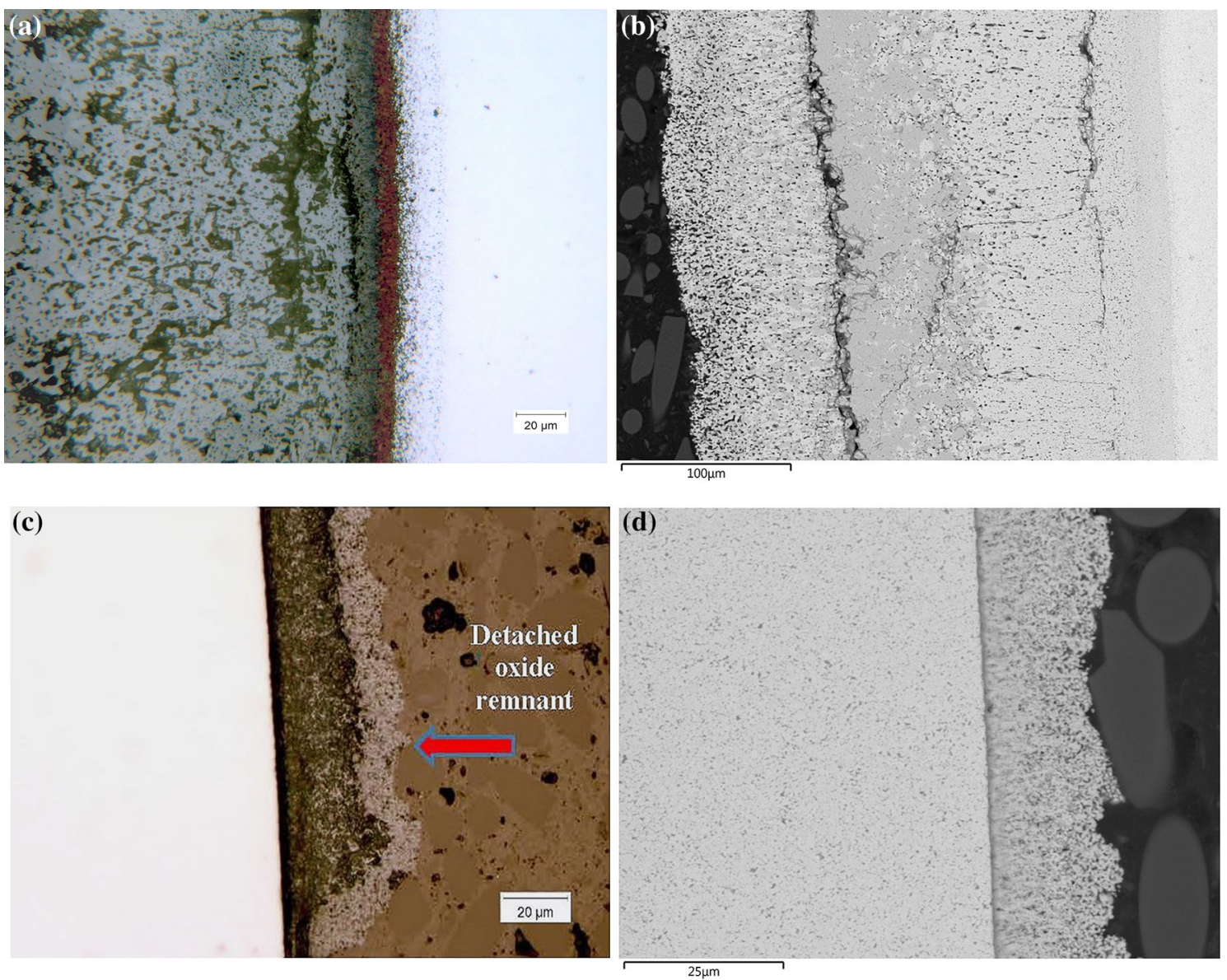

Fig. 18 Light microscope and SEM images of ID and OD cermet/oxide transition areas selected for linescan analysis. Exposed at $1000{ }^{\circ} \mathrm{C} / 1 \mathrm{~h}$

densities appear to be identical for $\mathrm{W}$ and Co, so it is not clear whether Co is important in this growth mode, or whether the Co map simply reflects the intimate mixture of $\mathrm{W}$ and $\mathrm{Co}$ in the cermet.

Spiral formations occur in a few binary alloy eutectic structures (e.g., Al-Mg, $\mathrm{Zn}-\mathrm{Mg}$ ), but these develop from growth anisotropy in the liquid phase. In this case, reactions are chemical between a gas and a solid. A more rigorous investigation is needed to determine how stresses generated by contiguous $\mathrm{W}-\mathrm{O}, \mathrm{Co}-\mathrm{O}$, and $\mathrm{W}-\mathrm{Co}-\mathrm{O}$ compound formation lead to this spiral structure on the reaction interface. In addition, it should be noted that this apparent 2D "spiral" may be a 3D helix, which becomes an integral part of the basal oxide structure developed over time. Such helix formations may be limited by continued oxidation of WC on the helical bands, so that they simply become consumed as the oxide layer grows away from the reaction surface. An initial helical growth mode, however, would help to explain the departure from columnar propagation established at lower temperatures.

Linescan data were acquired from a mounted and polished sample exposed at $1000{ }^{\circ} \mathrm{C} / 1 \mathrm{~h}$. The etched microstructure shown in Fig. 18a exhibits a striking ruby-red band close to the ID reaction interface, but just inside the oxide layer. An investigation of color compounds of $\mathrm{W}$ and Co ruled out the possibility that this was an oxide. It is more likely that this is a color generated during metallographic preparation. Water reaction with cobalt can produce $\left[\mathrm{Co}\left(\mathrm{H}_{2} \mathrm{O}\right)_{6}\right]^{2+}$ ions. The reason why Co in this location, just within the oxide layer, is so sensitive to reaction with water is not known. This reaction was not observed elsewhere.

Light microscope and SEM images, depicting reactions at $1000{ }^{\circ} \mathrm{C}$ (Fig. 18), suggest that inward diffusion of oxygen has taken place on the ID surface. Linescan data (Fig. 19) produced a very different picture from the one obtained at $700{ }^{\circ} \mathrm{C}$. Within the reaction zone, several bands, apparently containing different compounds (A, B, and C. D is substrate), are discernible on the backscattered electron image. Zone $\mathrm{C}$, with a thickness of $120 \mu \mathrm{m}$, does not show clear indications of element diffusion, but there is definite substrate bonding, substantial enough to resist oxide layer separation on cooling.

Zone $\mathrm{C}$ is also notable for the flat cobalt profile. Neither binder element, $\mathrm{Co}$ and $\mathrm{Cr}$, was detected in this zone, 


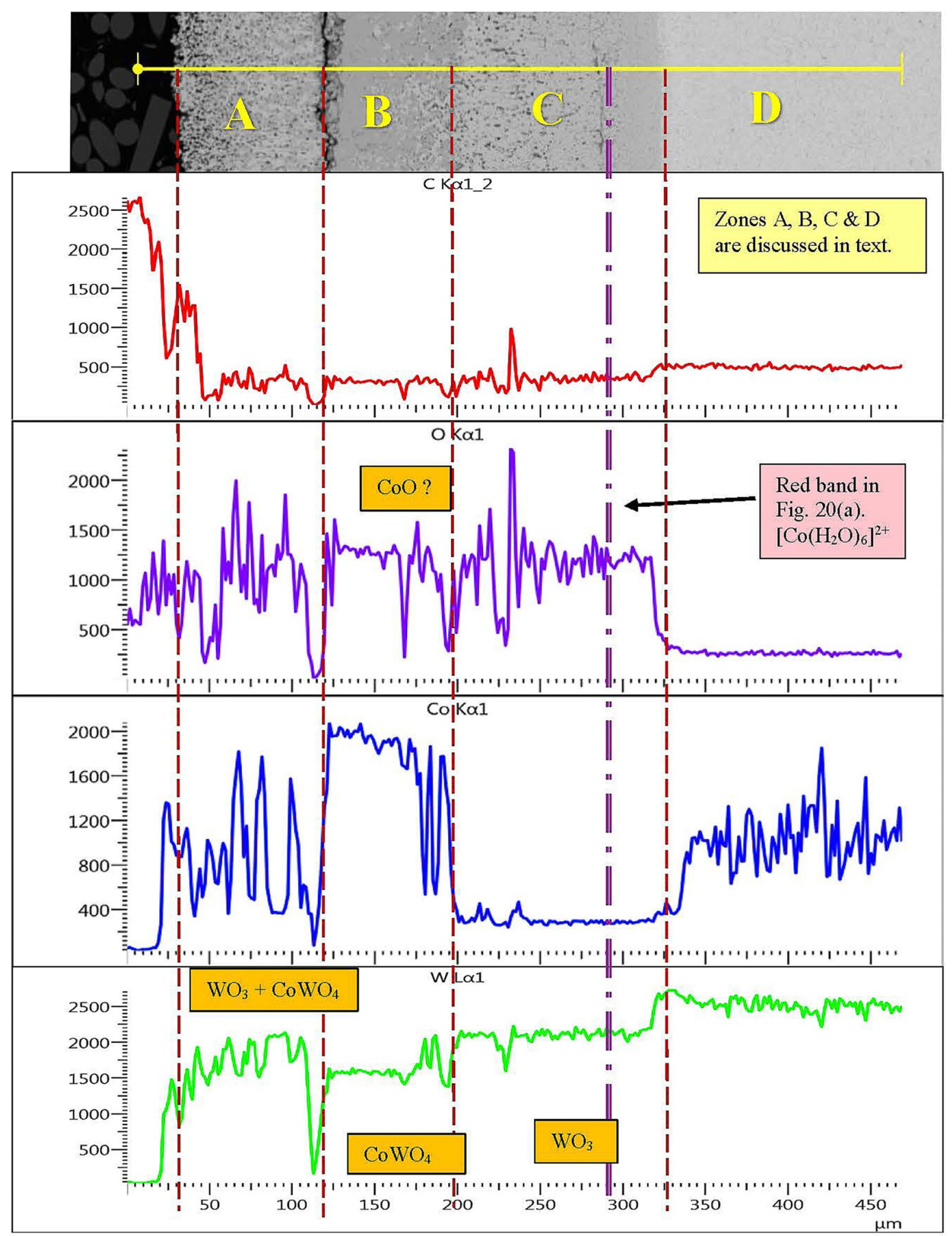

Fig. 19 Linescan data obtained across the ID substrate/oxide interface. Exposed at $1000{ }^{\circ} \mathrm{C} / 1 \mathrm{~h}$. Possible oxide constituents are indicated

indicating concentrations of less than $1.0 \mathrm{wt} . \%$. In contrast, oxygen is at its highest level of the four zones and has clearly reacted with tungsten to form $\mathrm{WO}_{3}$.
It would appear that the A/B Zone boundary may have been at the original ID surface. The following reactions are taking place at $1000^{\circ} \mathrm{C}$ : 


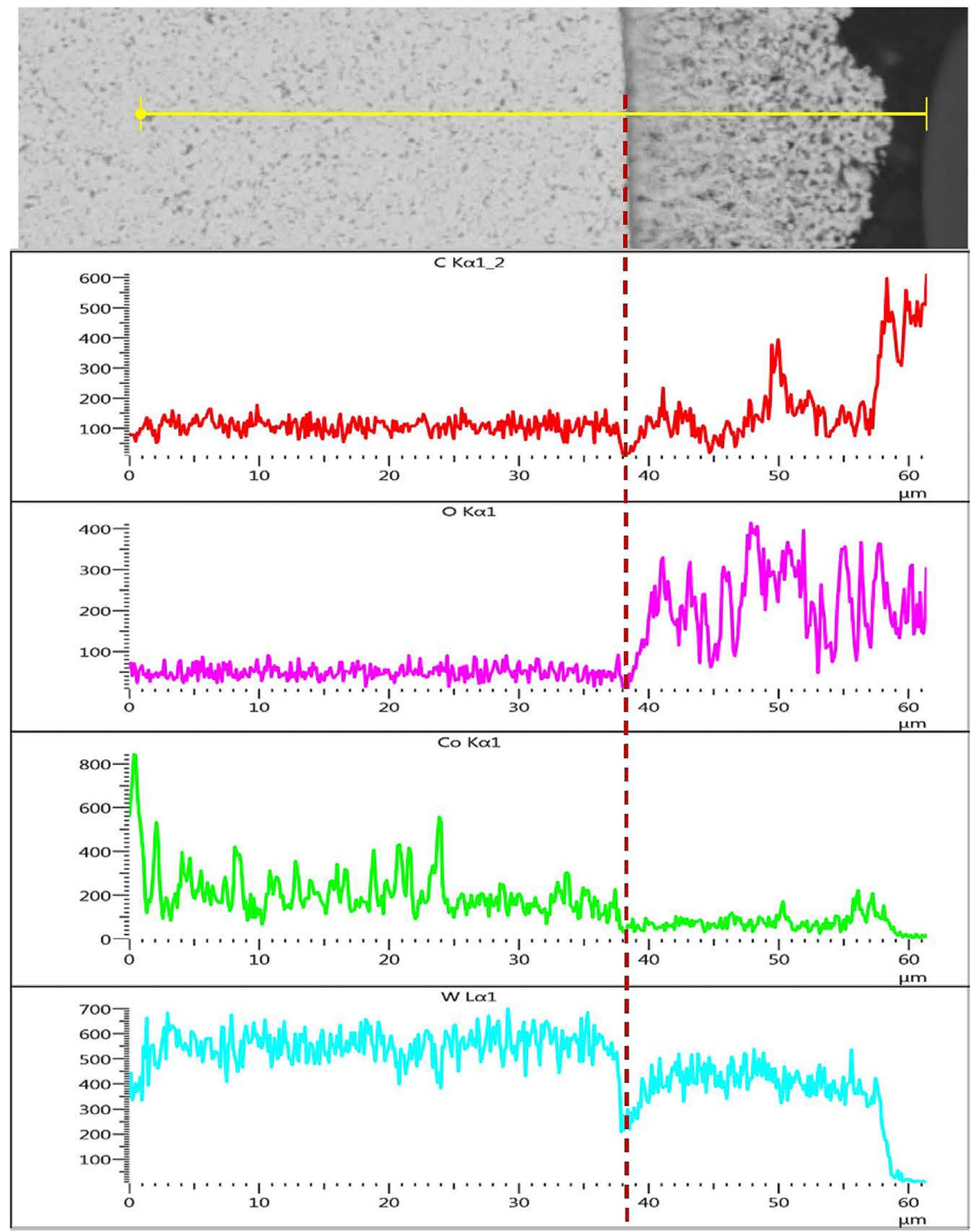

Fig. 20 Linescan data obtained across the OD substrate/oxide interface. No observable inward diffusion of oxygen. Exposed at $1000{ }^{\circ} \mathrm{C} / 1 \mathrm{~h}$

- Zone A: Oxygen reacts with the surface to form $\mathrm{WO}_{3}$ and $\mathrm{CoWO}_{4}$.

- Zone B: Oxygen diffuses into the bulk material, principally along the $\mathrm{WC} /$ binder interfaces. Outward diffusion of binder ( $\mathrm{Co}$ and $\mathrm{Cr}$ ) contributes to the formation of $\mathrm{CoO}$ and $\mathrm{CoWO}_{4}$ (and possibly $\mathrm{CoCrO}_{4}$ ).
- Zone C: This zone is depleted of binder, but inward diffusion of oxygen generates a band of $\mathrm{WO}_{3}$. Near the interface with Zone D, a layer sufficiently rich in Co reacts with water to produce a red color on the metallographic mount. 
Table 2 EDS analysis of areas A, B, C, and D (Fig. 19)

\begin{tabular}{lcccccc}
\hline Sample area & $\mathrm{C}$ & $\mathrm{O}$ & $\mathrm{Cr}$ & $\mathrm{Co}$ & $\mathrm{W}$ & Total \\
\hline (a) Weight\% & & & & & & \\
A & 3.9 & 22.5 & 0.7 & 8.3 & 64.6 & 100.0 \\
B & 3.0 & 23.2 & 1.1 & 14.0 & 58.7 & 100.0 \\
C & 3.4 & 23.6 & $\ldots$ & $\ldots$ & 73.0 & 100.0 \\
D & 6.7 & 1.4 & 0.5 & 6.0 & 85.4 & 100.0 \\
(b) Atomic\% & & & & & & \\
A & 14.7 & 62.7 & 0.6 & 6.3 & 15.7 & 100.0 \\
B & 11.1 & 63.6 & 0.9 & 10.4 & 14.0 & 100.0 \\
C & 13.0 & 68.5 & $\ldots$ & $\ldots$ & 18.4 & 100.0 \\
D & 45.4 & 7.3 & 0.7 & 8.4 & 38.1 & 100.0 \\
\hline
\end{tabular}

Table 3 Residual carbon after oxidation of WC-6\% Co

\begin{tabular}{ll}
\hline Oxidation exposure & $\begin{array}{l}\text { Residual } \\
\text { carbon } \\
\text { (wt.\%) }\end{array}$ \\
\hline $700{ }^{\circ} \mathrm{C} / 10 \mathrm{~h}$ & 0.020 \\
$850{ }^{\circ} \mathrm{C} / 10 \mathrm{~h}$ & 0.007 \\
$1000{ }^{\circ} \mathrm{C} / 1 \mathrm{~h}$ & 0.010 \\
\hline
\end{tabular}

- Zone D: Chemistry abruptly changes to original matrix. There is very little evidence of any element diffusion (in or out) beyond the $\mathrm{C} / \mathrm{D}$ boundary.

This complex oxide surface structure has formed in the constricting environment of the annulus ID. Development of compressive stress, produced by the natural tendency for expansion as tungsten oxide is formed, has closed cracks and other major oxide defects. Inward diffusion of oxygen creates three distinct layers as it meets zones with different chemistry. At $1000 \mathrm{C}$, it appears that diffusion of the Co binder phase has been activated across distinct zones (Zones $\mathrm{C} \rightarrow$ $\mathrm{B}$, and A in Fig. 19). Throughout the zones, WC reacts "in situ" allowing oxygen to move inward along the major phase interfaces. After $1 \mathrm{~h}$ at $1,000{ }^{\circ} \mathrm{C}$, the combined zones have developed to a thickness of $300 \mu \mathrm{m}$. Overall porosity, chiefly resulting from $\mathrm{WO}_{3}$ formation, allows $\mathrm{CO}_{2}$ to escape without creating major defects in the layered structure.

A linescan across the OD surface oxide (remnant), shown in Fig. 20, presents element reaction profiles consistent with the unreacted shrinking core mechanism. There is one clearly defined reaction interface, which separates oxidized substrate from the unoxidized core. These data are in sharp contrast to results obtained from the reaction zone on the ID surface of the annulus. In addition, as illustrated in Fig. 7, the OD oxide has grown to a thickness of about $5 \mathrm{~mm}$ in

Table 4 Summary of chemical and physical reactions during oxidation of WC-6\% Co cermet over the $700-1100{ }^{\circ} \mathrm{C}$ temperature range

\begin{tabular}{|c|c|c|c|c|}
\hline $700-800{ }^{\circ} \mathrm{C}$ & $850-950^{\circ} \mathrm{C}$ & $950{ }^{\circ} \mathrm{C}$ & $1000-1100{ }^{\circ} \mathrm{C}$ & Applicable reactions \\
\hline$*$ & * & $*$ & & Unreacted shrinking core oxidation model \\
\hline$*$ & $*$ & $*$ & & $\mathrm{WC}+(5 / 2) \mathrm{O}_{2} \Rightarrow \mathrm{WO}_{3}+\mathrm{CO}_{2}$ \\
\hline$*$ & & & & $\mathrm{WO}_{3}$ and $\mathrm{CoWO}_{4}$ \\
\hline \multirow{11}{*}{$*$} & $*$ & $*$ & & $\mathrm{Co}_{3} \mathrm{O}_{4} \Rightarrow 3 \mathrm{CoO}+1 / 2 \mathrm{O}_{2}$ \\
\hline & & $*$ & & $\mathrm{Co}+1 / 2 \mathrm{O}_{2}=\mathrm{CoO}$ \\
\hline & & & $*$ & Volatilization of $\mathrm{WO}_{3}$ \\
\hline & $*$ & & & Columnar growth \\
\hline & & $*$ & $*$ & Loss of columnar growth \\
\hline & $*$ & $*$ & $*$ & Increase in $\mathrm{CO}_{2}$ production leads to more porosity \\
\hline & $*$ & $*$ & $*$ & Increase in oxidation rate \\
\hline & & $*$ & $*$ & Helical nucleation? \\
\hline & & & $*$ & Spiral/helical growth on substrate \\
\hline & & & * & $\begin{array}{l}\text { Constricted geometry } \\
\text { Inward diffusion of } \mathrm{O} \text { to substrate }\end{array}$ \\
\hline & & & * & $\begin{array}{l}\text { Constricted geometry } \\
\text { Development of a diffusion zone below original surface }\end{array}$ \\
\hline
\end{tabular}


$1 \mathrm{~h}$. A summary of physical and chemical reactions occurring over the $700-1100{ }^{\circ} \mathrm{C}$ temperature range is presented in Table 4.

The phenomenon of "oxide jacking" is well known for damage inflicted by stresses generated during oxide growth and the accompanying volume expansion, on ferritic steel. Damage in structures of all kinds has been documented, from historic buildings to bridges, and even to granite countertops. In a confined space, oxidation of iron proceeds with the interdiffusion of oxygen into the steel and iron diffusion into the oxide. A large volume expansion of the oxide accompanies this process, and according to Harris, an early protagonist of this process, “...stresses generated are of sufficient magnitude to deform or fracture all known materials" [14].

Although volume expansion accompanying oxide growth of tungsten carbide is substantial, it would appear that in a constricted space at elevated temperature, the oxidation process is arrested or slowed down, due to inability of oxygen to reach the unreacted WC surface. The magnitude of compressive stress required to achieve this is not known. However, the overriding advantage of the shrinking core oxidation mechanism is that it only requires ingress of oxygen to the unreacted surface to be stopped. This is achieved by the self-generated pressure of oxide growth, which seals off fissures and other defect diffusion pathways in the oxide layer. In contrast to the oxide jacking process at ambient temperatures, oxide formation on a WC cermet in an ID annular space, for example, can become protective at very high temperatures.

Although the bushing sample geometry is not ideally suited for making accurate mass change measurements as a function of oxidation time and exposure temperature, an attempt to determine activation energy for the reaction was made. Employing the parabolic rate law for oxidation of WC- $6 \%$ Co over the temperature range of $600-850{ }^{\circ} \mathrm{C}$ to obtain a rate constant and then fitting this into the Arrhenius equation, an activation energy of $259 \mathrm{~kJ} / \mathrm{mol}$ was obtained.

Within the limits of tools available for this study, our results support an unreacted shrinking core model for oxidation of WC- $6 \%$ Co cermet. These experiments have expanded the oxidation reaction timescale and increased the temperature range. It is understood that in relation to oxidation experienced by tool bits, exposure periods in terms of minutes are more appropriate. However, observations made on the small bushing may lead to use of WC cermets in hightemperature bearings or other applications where annular geometry is utilized.

Acknowledgments The authors would like to recognize the valuable contributions made to this work by Paul Spiering and Matt Welc at Product Evaluation Systems, Inc, for the care taken with photography, heat treatment schedules, and metallography and to Chris Holp at First Energy Corp., BETA Lab. for his expertise with Scanning Electron Microscopy.

\section{References}

1. S.N. Basu, V.K. Sarin, Oxidation behavior of WC-Co. Mater. Sci. Eng. A 209, 206-212 (1996)

2. A.S. Kurlov, A.I. Gusev, Oxidation of tungsten carbide powders in air. Int. J. Refract. Metals Hard Mater. 41, 300-307 (2013)

3. N. Birks, G.H. Meier, Introduction to High Temperature Oxidation of Metals (Edward Arnold, London, 1983), p. 119

4. M. Aristizabal, J.M. Sanchez, N. Rodriguez, F. Ibarreta, R. Martinez, Comparison of the oxidation behavior of WC-Co and WC$\mathrm{Ni}-\mathrm{Co}-\mathrm{Cr}$ cemented carbides. Corros. Sci. 53, 2754-2760 (2011)

5. V.B. Voitovich, V.V. Sverdel, R.F. Voitovich, E.I. Golovko, Oxidation of $\mathrm{WC}-\mathrm{Co}, \mathrm{WC}-\mathrm{Ni}$ and $\mathrm{WC}-\mathrm{Co}-\mathrm{Ni}$ hard metals in the temperature range $500-800{ }^{\circ} \mathrm{C}$. Int. J. Hard Metals Hard Mater. 14(4), 289-295 (1996)

6. S.A. Humphrey-Baker, W.E. Lee, Tungsten carbide is more oxidation resistant than tungsten when processed to full density. Scr. Mater. 116, 67-70 (2016)

7. L. Chen, D. Yi, B. Wang, H. Liu, C. Wu, X. Huang, H. Li, Y. Gao, The selective oxidation behavior of WC-Co cemented carbides during the early oxidation stage. Corros. Sci. 94, 1-5 (2015)

8. E.A. Gulbransen, K.F. Andrews, The kinetics of the oxidation of cobalt. J. Electrochem. Soc. 98, 241-245 (1951)

9. L. Chen, D. Yi, B. Wang, H. Liu, C. Wu, Mechanism of the early stages of oxidation of WC-Co cemented carbides. Corros. Sci. 103, 75-87 (2016)

10. B. Pieraggi, Calculations of parabolic reaction rate constants. Oxid. Metals 27(3/4), 177-185 (1987)

11. D. Monceau, B. Pierragi, Determination of parabolic rate constants from a local analysis of mass-gain curves. Oxid. Metals 50(5/6), 477-493 (1998)

12. ASM Ready Reference, Thermal Properties of Metals (ASM International, Materials Park, 2002)

13. H. Na, Y. Eun, M.-O. Kim, J. Choi, J. Kim, Low-temperature selective growth of tungsten oxide nanowires by controlled nanoscale stress induction. Sci. Rep. 5, 18265 (2015)

14. J.E. Harris, in Oxidation induced deformation and fracture, Proceedings of the 6th International Conference on Fracture, New Delhi, India, vol 6 (Pergamon Press), pp 3791-3811, 4-10 December, 1984 